\title{
Guide for Current Nutrigenetic, Nutrigenomic, and Nutriepigenetic Approaches for Precision Nutrition Involving the Prevention and Management of Chronic Diseases Associated with Obesity
}

\author{
Omar Ramos-Lopez ${ }^{\text {a, b }}$ Fermín I. Milagrob,c Hooman Allayee ${ }^{d} \quad$ Agata Chmurzynska $^{\text {e }}$ \\ Myung Sook Choif ${ }^{f}$ Rui Curig Raffaele De Caterinah ${ }^{\text {h }}$ Lynnette R. Ferguson $^{\mathrm{i}}$ \\ Leticia Goni $^{b}$ Jing X. Kang ${ }^{j}$ Martin Kohlmeierk Amelia Martib, ${ }^{b}$ Luis A. Moreno' \\ Louis Pérusse $^{m} \quad$ Chandan Prasad $^{\text {n, o }} \quad$ Lu Qi $^{p}$, q Ram Reifen $^{r} \quad$ Jose I. Riezu-Boj ${ }^{b, s}$ \\ Rodrigo San-Cristobal ${ }^{b}$ Jose Luis Santos ${ }^{t}$ J. Alfredo Martínez ${ }^{b, c, s, u}$

\begin{abstract}
aDepartment of Molecular Biology in Medicine, Civil Hospital of Guadalajara "Fray Antonio Alcalde" and Health Sciences University Center, University of Guadalajara, Guadalajara, Mexico; 'bepartment of Nutrition, Food Science and Physiology, University of Navarra, and Center for Nutrition Research, University of Navarra, Pamplona, and ' CIBERobn, Physiopathology of Obesity, Carlos III Institute, Madrid, Spain; ${ }^{d}$ Institute for Genetic Medicine and Department of Preventive Medicine, USC Keck School of Medicine, Los Angeles, CA, USA; ${ }^{e}$ Department of Human Nutrition and Hygiene, Poznan University of Life Sciences, Poznan, Poland; ${ }^{f}$ Center for Food \& Nutritional Genomics, Department of Food Science \& Nutrition, Kyungpook National University, Daegu, Korea; 9 Department of Physiology and Biophysics, Institute of Biomedical Sciences, University of São Paulo, Butantan, São Paulo, Brazil; hInstitute of Cardiology "G. d'Annunzio" University and Center of Excellence on Aging, Chieti, Italy; iDiscipline of Nutrition and Auckland Cancer Society Research Centre, FM \& HS, and Nutrigenomics New Zealand, University of Auckland, Auckland, New Zealand; ' Laboratory for Lipid Medicine and Technology, Department of Medicine, Massachusetts General Hospital and Harvard Medical School, Boston, MA, and kDepartment of Nutrition, School of Public Health, School of Medicine, University of North Carolina at Chapel Hill, Chapel Hill, NC, USA; 'GENUD (Growth, Exercise, NUtrition and Development) Research Group, Faculty of Health Sciences, University of Zaragoza, Zaragoza, Spain; m Department of Kinesiology and Institute of Nutrition and Functional Foods, Université Laval, Québec City, QC, Canada; n'Department of Nutrition and Food Sciences, Texas Woman's University, Denton, TX, ${ }^{\circ}$ Department of Medicine, Section of Endocrinology, LSU Health Sciences Center, and PDepartment of Epidemiology, School of Public Health and Tropical Medicine, Tulane University, New Orleans, LA, and 9Department of Nutrition, Harvard T.H. Chan School of Public Health, Boston, MA, USA; ' Department of Biochemistry and Food Sciences, The Robert H. Smith Faculty of Agriculture, Food and Environment, The Hebrew University of Jerusalem, Jerusalem, Israel; ${ }^{\mathrm{s}}$ Navarra Institute for Health Research (IdiSNA), Pamplona, Spain; 'Department of Nutrition, Diabetes and Metabolism, School of Medicine, Pontificia Universidad Católica de Chile, Santiago, Chile; "Madrid Institute of Advanced Studies (IMDEA Food), Madrid, Spain
\end{abstract}

This paper was presented at the 10th Congress of the International Society of Nutrigenetics/Nutrigenomics (ISNN), Tel Aviv, May 22-26, 2016.

Prof. J. Alfredo Martínez

Department of Nutrition, Food Science and Physiology, University of Navarra Irunlarrea 1

ES-31008 Pamplona (Spain)

E-Mail jalfmtz @ unav.es 


\title{
Keywords
}

Genes - Polymorphisms · DNA methylation - Transcriptomics · miRNA · Biomarkers · Diet · Precision nutrition · Obesity $\cdot$ Chronic diseases

\begin{abstract}
Chronic diseases, including obesity, are major causes of morbidity and mortality in most countries. The adverse impacts of obesity and associated comorbidities on health remain a major concern due to the lack of effective interventions for prevention and management. Precision nutrition is an emerging therapeutic approach that takes into account an individual's genetic and epigenetic information, as well as age, gender, or particular physiopathological status. Advances in genomic sciences are contributing to a better understanding of the role of genetic variants and epigenetic signatures as well as gene expression patterns in the development of diverse chronic conditions, and how they may modify therapeutic responses. This knowledge has led to the search for genetic and epigenetic biomarkers to predict the risk of developing chronic diseases and personalizing their prevention and treatment. Additionally, original nutritional interventions based on nutrients and bioactive dietary compounds that can modify epigenetic marks and gene expression have been implemented. Although caution must be exercised, these scientific insights are paving the way for the design of innovative strategies for the control of chronic diseases accompanying obesity. This document provides a number of examples of the huge potential of understanding nutrigenetic, nutrigenomic, and nutriepigenetic roles in precision nutrition.

(C) 2017 S. Karger AG, Basel
\end{abstract}

\section{Introduction}

Obesity is a global epidemic with more than $35 \%$ of the world population $(2,100$ million people) being estimated as either overweight or obese according to body mass index (BMI) [1]. Obesity is associated with a large number of health problems including dyslipidemias, cardiovascular diseases (CVD), type 2 diabetes mellitus (T2DM), non-alcoholic fatty liver disease (NAFLD), and some types of cancer, with important economic and social costs [2]. Systematic analyses have revealed that obesity and overweight caused 3.4 million deaths in 2010 [3].

The long-term consumption of unbalanced diets (high content of calories, fat, fructose and high omega-6/omega-3 fatty acid ratio), coupled with the adoption of a sedentary lifestyle, contributes to the development of obesity and associated complications [4, 5]. Also, it is now recognized that interactions of genetic and epigenetic signatures with environmental factors (dietary intake or physical activity) play an important role in determining individual phenotypes [6,7]. Recent advances in genomic sequencing and large cohort studies are enabling clarification of the involvement and the interplay of these factors in chronic disorders including obesity, which open a new field to customize intervention strategies [8, 9]. Precision medicine refers to disease therapeutics based on interindividual differences, such as genetic profile, phenotype, gender, microbiome, and environmental features [10]. In this context, precision nutrition is an important part of precision medicine that may aid in establishing nutritional guidelines for specific subgroups instead of conventional population-based advice [11].

Herein, we review genetic and epigenetic biomarkers related to obesity, dyslipidemia, T2DM, CVD, NAFLD, and some types of cancer that may serve to understand disease etiology and outline future therapeutic targets and treatments. In this sense, responses to dietary interventions, mainly aimed at weight reduction and management of metabolic disorders 
Fig. 1. Nutrigenetic, nutrigenomic, and nutriepigenetic approaches for precision nutrition to the prevention and management of obesity and associated chronic diseases.

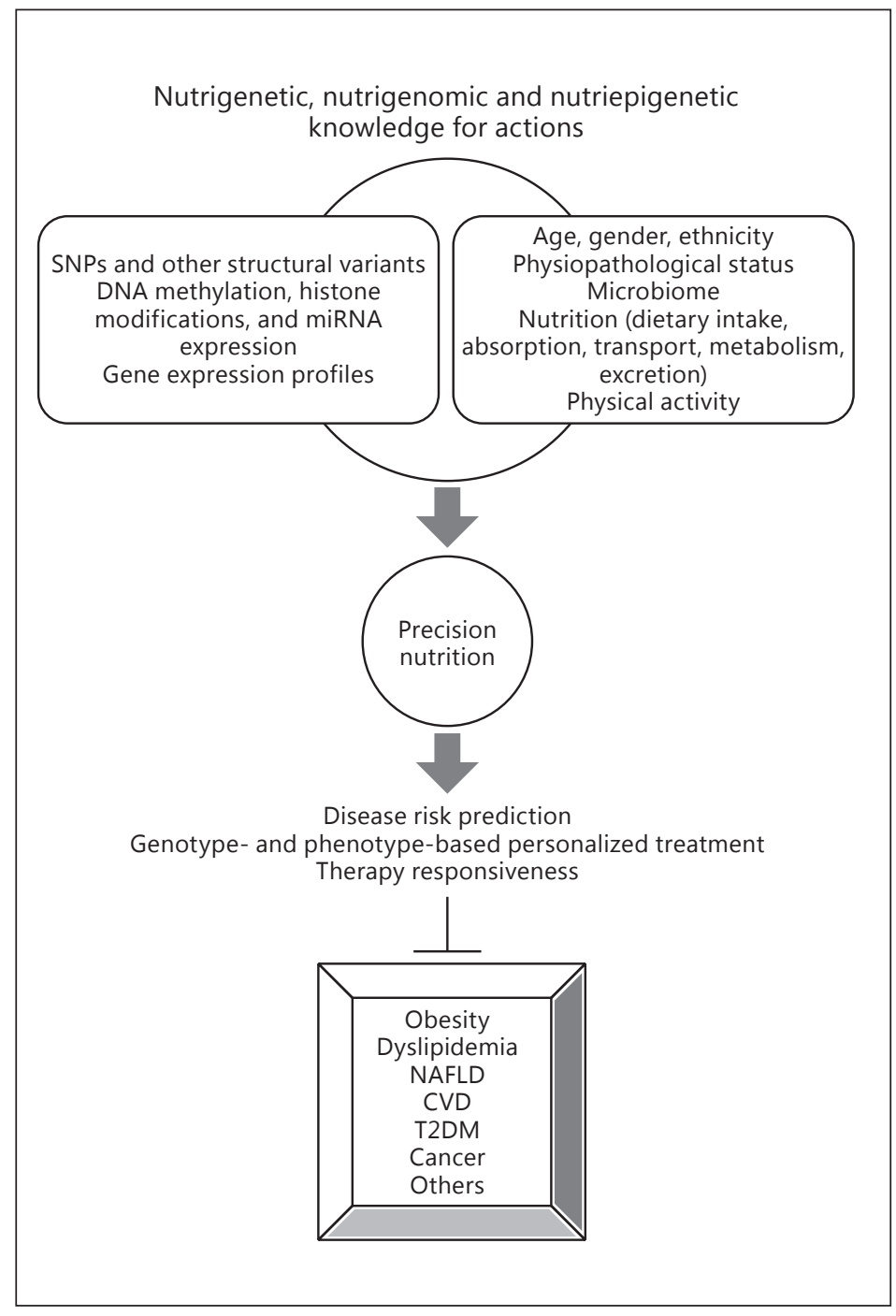

(i.e., insulin resistance, dyslipidemias, fatty liver), are screened for their interaction with genetic and epigenetic features. Also, nutritional interventions based on certain specific nutrients and bioactive dietary compounds that can modify epigenetic marks and gene expression are reviewed. The integration of the emerging knowledge derived from different genetic and epigenetic approaches is required in order to outline new therapeutic tools for advancing in the prevention and personalized management of chronic diseases through precision nutrition (Fig. 1).

\section{Genetic Background and Nutritional Prescriptions}

International genome projects using whole-genome sequencing analyses have provided a comprehensive description of genetic variations across the human genome including single nucleotide polymorphisms (SNPs), copy number variations (CNVs), and other structural variants [12]. In recent years, nutrigenetic studies have allowed the identification of genetic variants associated with disease susceptibility through interaction with dietary factors [13]. 
Table 1. Nutrigenetic examples of SNPs-diet interactions involved in disease risk

\begin{tabular}{|c|c|c|c|c|c|}
\hline Genes & Polymorphisms & Alleles & Diet interactions & Putative disease risks & Ref. \\
\hline TAS1R2 & rs35874116 & $\mathrm{G}$ & High carbohydrate & Hypertriglyceridemia & [16] \\
\hline CD36 & rs1761667 & $\mathrm{A}$ & High fat, SFA & Hypercholesterolemia & {$[17]$} \\
\hline MTHFR & rs1801133 & $\mathrm{T}$ & $\begin{array}{l}\text { Low folate, vitamin } B_{6} \text {, and } \\
\text { vitamin } B_{12}\end{array}$ & Breast cancer & [18] \\
\hline$\overline{M T R}$ & rs1805087 & $\mathrm{G}$ & $\begin{array}{l}\text { Low folate, vitamin } B_{6} \text {, and } \\
\text { vitamin } B_{12}\end{array}$ & Breast cancer & [18] \\
\hline$\overline{V D R}$ & rs1544410 & $\mathrm{A}$ & Low calcium & Osteoporosis & {$[22]$} \\
\hline APOC3 & rs5128 & $\mathrm{C}$ & Western dietary pattern & Metabolic syndrome & [23] \\
\hline$A P O A 1$ & rs670, rs5069 & $\mathrm{A}, \mathrm{T}$ & Western dietary pattern & Metabolic syndrome & [24] \\
\hline CYP1A2 & rs762551 & $\mathrm{C}$ & $\begin{array}{l}\text { Moderate and heavy coffee } \\
\text { drink }\end{array}$ & Hypertension, CVD & {$[25,26]$} \\
\hline FTO & rs9939609 & $\mathrm{T}$ & $\begin{array}{l}\text { Low adherence to } \\
\text { Mediterranean diet }\end{array}$ & T2DM & {$[106]$} \\
\hline$M C 4 R$ & rs17782313 & $\mathrm{T}$ & $\begin{array}{l}\text { Low adherence to } \\
\text { Mediterranean diet }\end{array}$ & T2DM & {$[106]$} \\
\hline FTO & rs9939609 & $\mathrm{A}$ & High fat & Obesity & {$[107,108]$} \\
\hline FTO & rs8050136 & A & High carbohydrate & Obesity & [109] \\
\hline$M C 4 R$ & rs12970134 & A & $\begin{array}{l}\text { Western dietary pattern } \\
\text { and high SFA }\end{array}$ & Metabolic syndrome & [110] \\
\hline$A P O B$ & rs512535 & $\mathrm{G}$ & High fat & Metabolic syndrome & {$[111]$} \\
\hline TCF7L2 & rs7903146 & $\mathrm{T}$ & High dessert and milk & T2DM & [112] \\
\hline TCF7L2 & rs7903146 & $\mathrm{T}$ & High SFA & Metabolic syndrome & {$[113]$} \\
\hline$L C T$ & rs4988235 & $\mathrm{T}$ & High dairy products & Obesity & [114] \\
\hline PPARG & rs1801282 & $\mathrm{G}$ & High fat & Obesity & [115] \\
\hline PNPLA3 & rs739409 & $\mathrm{G}$ & High carbohydrate & NAFLD & [116] \\
\hline$T X N$ & rs2301241 & $\mathrm{T}$ & Low vitamin $\mathrm{E}$ & Abdominal obesity & [117] \\
\hline
\end{tabular}

MTHFR, methylenetetrahydrofolate reductase; MTR, methionine synthase; FTO, fat mass and obesity associated; $M C 4 R$, melanocortin 4 receptor; $A P O C 3$, apolipoprotein C3; $A P O A 1$, apolipoprotein A1; $A P O B$, apolipoprotein B; CD36, cluster of differentiation 36; TCF7L2, transcription factor 7 like 2; $L C T$, lactase; $P P A R G$, peroxisome proliferator activated receptor gamma; PNPLA3, patatin like phospholipase domain containing 3; TAS1R2, taste 1 receptor member 2; VDR, vitamin D receptor; CYP1A2, cytochrome P450 family 1 subfamily A member 2; TXN, thioredoxin; SFA, saturated fatty acids; MUFA, monounsaturated fatty acids; T2DM, type 2 diabetes mellitus; CVD, cardiovascular disease.

These scientific advances are contributing to the prevention and treatment of chronic diseases since they potentially allow to (1) predict individual risks, (2) explain their etiology, and (3) enable the personalization of their nutritional management [14, 15].

Indeed, SNPs (or more generally speaking, SNV, single nucleotide variants, a term that comprises both common and low-frequency alleles) are by far the most widely studied genetic variation in the field of precision nutrition. In this sense, several SNPs have been associated with common chronic diseases through interactions with the intakes of macroand micronutrients, or with the consumption of particular foods and dietary patterns (Table 1). Examples include polymorphisms in genes related to taste perception including the sweet taste receptor (TAS1R2) [16] and cluster of differentiation 36 (CD36) [17], which were associated with dyslipidemia in Mexican subjects consuming high amounts of carbohydrates and fats, respectively. Common variants in genes regulating homocysteine metabolism, such as methylenetetrahydrofolate reductase (MTHFR), and methionine synthase $(M T R)$, have been linked to increased risk for breast cancer in individuals with low intakes of folate, vitamin $\mathrm{B}_{6}$, and vitamin $\mathrm{B}_{12}$ [18]. Also, it has been reported that in addition to 
sunlight, vitamin D status can also be influenced by several polymorphisms in vitamin D pathway genes [19], thereby modulating its biological functions in the organism. Interestingly, SNPs in the vitamin D receptor (VDR) gene, which affect vitamin D availability [20,21], have been associated with osteoporosis predisposition in postmenopausal women with low calcium intakes [22]. Moreover, SNPs in genes encoding lipid proteins such as apolipoprotein C3 (APOC3) and apolipoprotein A1 (APOA1) conferred a higher risk of metabolic syndrome in subjects with a Western dietary pattern $[23,24]$. Likewise, a genetic variant in the cytochrome P450 family 1 subfamily A member 2 (CYP1A2) gene was associated with an increased risk of hypertension and CVD in moderate and heavy coffee drinkers [25, 26]. Additionally, studies using genetic risk scores (GRS) have examined the cumulative effect of SNPs on diet interactions and disease susceptibility. Thus, macronutrient intake was shown to modify the association of an obesity GRS with greater values of adiposity [27]. Significant interactions between saturated fat intake and obesity GRS were also found to modulate BMI in two American populations [28]. Furthermore, obesity GRS interacted with the intake of sugar-sweetened beverages [29], and fried food consumption [30] in relation to BMI and obesity in several cohort studies.

Nutrigenetics is defined as the science that studies the effect of genetic variation on dietary response [13]. Thus, SNPs-diet interactions have also been reported to be involved in the differential responses to nutritional interventions aimed at restricting total caloric intake or modifying energy derived from fat, protein, or carbohydrates (Table 2). In this sense, studies performed in a range of populations have investigated the effects of several SNPs on weight loss, weight regain and metabolic improvements concerning serum lipid levels and insulin resistance (Table 2). These investigations include polymorphisms in or near genes involved in the regulation of food intake, lipid and lipoprotein metabolism, insulin signaling, glucose homeostasis, inflammatory response, amino acid metabolism, and circadian cycle (Table 2). Regarding the effects of GRS on dietary responses, individuals with lower GRS for T2DM had greater improvements in insulin resistance and $\beta$-cell function when consuming a low-protein diet [31]. Conversely, subjects with higher GRS for glucose disorders had greater increases in fasting glucose when consuming a high-fat diet [32]. Moreover, a GRS built from genes identified by genome-wide association studies, partially explained the variation in triglyceride changes in response to omega-3 fatty acid supplementation [33].

Additionally, SNPs have been included in nutrigenetic tests with the aim of evaluating their impact on changing eating habits. For example, it was shown that gene-based personalized nutrition targeting the apolipoprotein $\mathrm{E}(A P O E)$ gene was more effective in reducing saturated fat intake compared with standard dietary advice [34]. Also, greater Mediterranean diet scores were reported among participants who received gene-based personalized nutrition targeting specific variants in five nutrient-responsive genes compared with those who received dietary advice on the basis of current diet plus phenotype [35]. Furthermore, it was reported that disclosure of genetic information regarding angiotensin I converting enzyme $(A C E)$ genotype for personalized nutrition resulted in greater changes in sodium intake compared to general population-based dietary advice [36]. Likewise, individuals who were informed about their fatty acid desaturase 1 (FADS1) genotype were more aware of the role of omega-3 fatty acids in health, and reported fewer barriers to their consumption, compared with those who did not receive their personal genetic information [37]. These findings are related to a better understanding, awareness, and usefulness of dietary recommendations based on genetics than general dietary advice [38].

In addition to SNPs, previous studies have found evidence of an association between CNVs and the risk of metabolic diseases. For example, CNV in the leptin receptor (LEPR) gene was found to be associated with metabolic traits and the risk of T2DM [39]. Moreover, 
Table 2. Certain nutrigenetic trials analyzing SNPs-diet interactions involved in the differential responses to nutritional interventions

\begin{tabular}{|c|c|c|c|c|c|}
\hline Genes & Polymorphisms & Alleles & Diet interactions & Dietary responses & Ref. \\
\hline FTO & rs1558902 & A & High protein & Greater weight loss & [118] \\
\hline FTO & rs1558902 & $\mathrm{A}$ & Low fat & $\begin{array}{l}\text { Less reductions in insulin and } \\
\text { HOMA-IR }\end{array}$ & [119] \\
\hline TCF7L2 & rs7903146 & $\mathrm{T}$ & High fat & Smaller weight loss and HOMA-IR & [120] \\
\hline APOA5 & rs964184 & $\mathrm{G}$ & Low fat & Greater reduction in TC and LDL-c & {$[121]$} \\
\hline$\overline{G I P R}$ & rs2287019 & $\mathrm{T}$ & Low fat & $\begin{array}{l}\text { Greater weight loss and greater } \\
\text { decreases in glucose, insulin and } \\
\text { HOMA-IR }\end{array}$ & [122] \\
\hline$\overline{C E T P}$ & rs3764261 & $\mathrm{C}$ & High fat & $\begin{array}{l}\text { Larger increases in HDL-c and } \\
\text { decreases in triglycerides }\end{array}$ & [123] \\
\hline$\overline{D H C R 7}$ & rs12785878 & $\mathrm{T}$ & High protein & $\begin{array}{l}\text { Greater decreases in insulin and } \\
\text { HOMA-IR }\end{array}$ & {$[124]$} \\
\hline$\overline{L I P C}$ & rs2070895 & A & Low fat & $\begin{array}{l}\text { Higher decreases in TC and LDL-c } \\
\text { and a lower increase } \\
\text { in HDL-c }\end{array}$ & {$[125]$} \\
\hline$\overline{P P M 1 K}$ & rs1440581 & $\mathrm{C}$ & High fat & $\begin{array}{l}\text { Less weight loss and smaller } \\
\text { decreases in insulin and HOMA-IR }\end{array}$ & [126] \\
\hline TFAP2B & rs987237 & $\mathrm{G}$ & High protein & Higher weight regains & [127] \\
\hline IRS1 & rs2943641 & $\mathrm{C}$ & High carbohydrate & $\begin{array}{l}\text { Greater decreases in insulin, } \\
\text { HOMA-IR and weight loss }\end{array}$ & [128] \\
\hline PCSK7 & rs236918 & $\mathrm{G}$ & High carbohydrate & $\begin{array}{l}\text { Higher decreases in insulin and } \\
\text { HOMA-IR }\end{array}$ & [129] \\
\hline MTNR1B & rs10830963 & $\mathrm{G}$ & High protein & Lower weight loss in women & [130] \\
\hline IL6 & rs2069827 & $\mathrm{C}$ & Mediterranean diet & Lower weight gains & [131] \\
\hline
\end{tabular}

FTO, fat mass and obesity associated; TCF7L2, transcription factor 7 like 2; APOA5, apolipoprotein A5; GIPR, gastric inhibitory polypeptide receptor; CETP, cholesteryl ester transfer protein; DHCR7, 7-dehydrocholesterol reductase; $L I P C$, lipase C, hepatic type; $P P M 1 K$, protein phosphatase, $\mathrm{Mg}^{2+} / \mathrm{Mn}^{2+}$ dependent $1 \mathrm{~K} ;$ TFAP2B, transcription factor AP-2 beta; IRS1, insulin receptor substrate 1; PCSK7, proprotein convertase subtilisin/kexin type 7; MTNR1B, melatonin receptor 1B; IL6, interleukin-6; TC, total cholesterol; LDL-C, low-density lipoprotein cholesterol; HDL-c, high-density lipoprotein cholesterol; HOMA-IR, homeostasis model assessment of insulin resistance.

low copy number of the salivary amylase alpha $1 \mathrm{~A}(A M Y 1 A)$ gene has been related to a predisposition for obesity, suggesting a link between carbohydrate metabolism and obesity $[40,41]$. Another DNA biomarker is the pentanucleotide (CTTTA) Del/Ins variant in the $3^{\prime}$-UTR of the LEPR gene, which has been associated with the risk of T2DM [42]. Further studies are needed to assess possible interactions between these genetic variants and dietary intake in relation to disease risk as well as their effects on dietary response, but such investigations provide examples of the direction in which future research in the field should be headed.

\section{Diet and Gene Expression Profiles}

Nutrition may exert an impact on health outcomes by directly affecting the expression of genes that regulate critical metabolic pathways [43]. In this sense, the science of nutrigenomics studies the role of nutrients and bioactive food compounds in gene expression and, 
Table 3. Nutrigenomic examples of interactions between dietary intakes and gene expression profiles involved in disease risk

\begin{tabular}{|c|c|c|c|c|}
\hline Dietary factors & Target genes & $\begin{array}{l}\text { Expression } \\
\text { changes }\end{array}$ & Putative disease risks & Ref. \\
\hline Low protein & NR1H3 & - & $\mathrm{T} 2 \mathrm{DM}$ & {$[47]$} \\
\hline Low protein & HSD11B1, PCK1 & + & T2DM & [47] \\
\hline Choline and folate deficiency & PPARGA & - & NAFLD & {$[48]$} \\
\hline Chromium deficiency & Insulin signaling genes & - & T2DM & [49] \\
\hline Selenium deficiency & TLR2, ICAM1 & + & CVD & [50] \\
\hline Vitamin $\mathrm{B}_{12}$ deficiency & SREBF1, LDLR & + & Dyslipidemia & {$[51]$} \\
\hline Vitamin A deficiency & GATA4 & - & CVD & [52] \\
\hline High fat and high sugar & LEP, SREBF1, PLIN & + & Obesity & [65] \\
\hline High fat & OPRM1, PENK, DAT & + & Obesity & {$[74]$} \\
\hline Low protein & CYP7A1 & - & Dyslipidemia & [75] \\
\hline Selenium deficiency & VHL & - & Cancer & [79] \\
\hline Vitamin D deficiency & NFKBIA & - & T2DM & {$[80]$} \\
\hline High SFA & TNFA, IL6 & + & CVD & [132] \\
\hline High SFA & $\begin{array}{l}\text { Proinflammatory } \\
\text { "obesity-linked" genes }\end{array}$ & + & Obesity-related inflammation & [133] \\
\hline High SFA & PPARGC1A & - & NAFLD & [134] \\
\hline High SFA & ADGRE1 & + & Obesity-related inflammation & [134] \\
\hline High fat & $L E P R, N P Y$ & + & Obesity & [135] \\
\hline High fat & $T H, D R D 4$ & + & Obesity & {$[136]$} \\
\hline High fat rich in lard & $\begin{array}{l}\text { OPN, ADGRE1, TNFA, } \\
\text { NFKB1 }\end{array}$ & + & $\begin{array}{l}\text { Obesity-related inflammation } \\
\text { and insulin resistance }\end{array}$ & [137] \\
\hline High fat rich in lard & $\begin{array}{l}\text { OPN, TLR2, TLR4, } \\
\text { TNFA }\end{array}$ & + & $\begin{array}{l}\text { Obesity-related inflammation } \\
\text { and insulin resistance }\end{array}$ & [138] \\
\hline High fat and high sugar & DRD2 & - & Obesity & [139] \\
\hline High fat and high sugar & $N P Y$ & + & Obesity & [140] \\
\hline High fat and high sugar & $P O M C$ & - & Obesity & [140] \\
\hline High carbohydrate & FGF21 & + & NAFLD & [141] \\
\hline Low folate and choline & $\begin{array}{l}\text { Genes involved in } \\
\text { cellular proliferation }\end{array}$ & + & Liver cancer & [142] \\
\hline $\begin{array}{l}\text { Western diet plus vitamin D } \\
\text { deficiency }\end{array}$ & $\begin{array}{l}\text { TLR2, TLR4, TLR9, IL1B, } \\
\text { IL4, IL6, RETN }\end{array}$ & + & NAFLD & [143] \\
\hline Choline and folate deficiency & APOE, FOXA1, FOXA2 & - & NAFLD & [144] \\
\hline
\end{tabular}

SFA, saturated fatty acids; TNFA, tumor necrosis factor alpha; IL6, interleukin-6; PPARGC1A, peroxisome proliferative activated receptor, gamma, coactivator 1 alpha; ADGRE1, adhesion G protein-coupled receptor E1; $L E P R$, leptin receptor; $N P Y$, neuropeptide Y; $T H$, tyrosine hydroxylase; $D R D 4$, dopamine receptor D4; OPRM1, opioid receptor, mu 1; $P E N K$, preproenkephalin; $D A T$, dopamine transporter; $O P N$, osteopontin; NFKB1, nuclear factor kappa B subunit 1; TLR2, toll-like receptor 2; TLR4, toll-like receptor 4; DRD2, dopamine receptor D2; POMC, proopiomelanocortin; $L E P$, leptin; SREBF1, sterol regulatory element binding transcription factor 1; PLIN, perilipin; FGF21, fibroblast growth factor 21; CYP7A1, cytochrome P450 family 7 subfamily A member 1; NR1H3, nuclear receptor subfamily 1 group $\mathrm{H}$ member 3 ; HSD11B1, hydroxysteroid 11-beta dehydrogenase 1; PCK1, phosphoenolpyruvate carboxykinase 1; TLR9, toll-like receptor 9; IL1B, interleukin-1 beta; IL4, interleukin-4; RETN, resistin; APOE, apolipoprotein E; FOXA1, forkhead box A1; FOXA2, forkhead box A2; PPARA, peroxisome proliferator activated receptor alpha; $L D L R$, low-density lipoprotein receptor; NFKBIA, NFKB inhibitor alpha; GATA4, GATA binding protein 4; ICAM1, intercellular adhesion molecule 1; VHL, von Hippel-Lindau; CVD, cardiovascular disease; T2DM, type 2 diabetes mellitus; NAFLD, nonalcoholic fatty liver disease.

consequently, on the proteome and the metabolome [44]. To date, a large number of studies have evaluated the effect of different dietary factors on gene expression profiles, which are related to disease susceptibilities (Table 3). With regard to dietary patterns, subjects following a Western dietary pattern, characterized by high intakes of refined grain products, desserts, sweets, and processed meats, showed a gene expression profile associated with inflammatory response and cancer signaling compared to those who consumed high amounts of vegetables, fruits, and whole grain products [45]. Similarly, pathway analyses revealed that high meat 
consumption was associated with gene networks linked to cancer in colon tissue [46]. High-fat diets, especially rich in saturated fatty acids, have induced gene expression profiles related to inflammation, glucose intolerance, and liver lipid accumulation, as well as upregulation of neuropeptide expression involved in obesity development (Table 3). On the other hand, lowprotein diets enhanced hepatic gluconeogenic gene expression with subsequent glucose intolerance [47]. Also, choline- and folate-deficient diets were associated with dysregulation of genes involved in lipid metabolism, thus influencing the susceptibility and severity of NAFLD [48]. Chromium deficiency downregulated insulin signaling genes, thus demonstrating a role in T2DM pathogenesis [49], whereas deprivations of selenium [50], vitamin $\mathrm{B}_{12}$ [51], and vitamin A [52], could increase CVD susceptibility by upregulating proinflammatory and lipogenic genes.

Experimental studies have shown the beneficial effects of nutrients and bioactive food compounds as a result of the regulation of critical gene expressions (Table 4). In this sense, it has been reported that consuming a Mediterranean diet reduces the postprandial expression of genes that encode proteins related to inflammation, endoplasmic reticulum stress, atherogenesis, and oxidative stress [53-55]. Also, high intakes of monounsaturated fatty acids through the consumption of olive oil have been associated with a low expression of genes involved in inflammation and abnormal lipid storage $[55,56]$. Diets with a high content of polyunsaturated fatty acids favorably regulate the expression of neuropeptide genes involved in energy homeostasis [57]. Moreover, energy-restricted diets supplemented with eicosapentaenoic acid, and $\alpha$-lipoic acid have been associated with upregulation of fatty acid-oxidizing genes, as well as downregulation of lipogenic and proinflammatory genes [58, 59]. In contrast, high-protein diets prevent and reverse NAFLD by modulating the expression of genes involved in liver lipid metabolism $[60,61]$. Concerning the effects of bioactive food compounds on gene expression, those most widely studied include green tea, theaflavin (black tea), sulforaphane (cruciferous vegetables), resveratrol (grapes and red wine), curcumin (turmeric), genistein (soy bean), and several apple polyphenols (Table 4). Thus, epigallocatechin-3-gallate, theaflavin, curcumin, sulforaphane, and genistein may exert anticancer properties by upregulating tumor suppressor genes and conversely, downregulating tumor promoting genes (Table 4). In addition, curcumin and resveratrol have shown antiatherogenic effects by decreasing the expression of matrix metalloproteinases, which are involved in plaque formation and progression [62-64]. Of note, apple polyphenols apparently prevented dietinduced obesity through the regulation of genes involved in adipogenesis, lipolysis, and fatty acid oxidation [65].

Interestingly, gene expression profiles have also been used to predict the responsiveness to nutritional treatments. In this area, it has been reported that, prior to the consumption of a low-fat diet, adipose gene expression profiling was able to differentiate responders from nonresponders, as well as serve as a weak predictor of subjects predisposed to lose weight [66]. Also, the analysis of gene expression in subcutaneous adipose tissue revealed that genes regulating fatty acid metabolism, citric acid cycle, oxidative phosphorylation, and apoptosis were differentially regulated during a low-calorie diet between weight maintainers and weight regainers after weight loss [67]. Moreover, expression levels of proinflammatory genes were higher at the end of a low-calorie diet in subjects who after dietary-induced weight loss subsequently regained weight [68]. Differentially expressed genes in adipose tissue were also observed between successful and unsuccessful subjects after an energy restriction-induced weight loss program [69]. In this study, pathway analyses revealed that the main biological processes represented in adipose tissue from subjects who regained weight included cellular growth and proliferation, cell death, cellular function, and maintenance, whereas mitochondrial oxidative phosphorylation was the major network associated with continued weight loss [69]. 
Table 4. Certain nutrigenomic studies assessing gene expression profiles associated with nutritional interventions

\begin{tabular}{|c|c|c|c|c|}
\hline Nutritional interventions & Target genes & $\begin{array}{l}\text { Expression } \\
\text { changes }\end{array}$ & $\begin{array}{l}\text { Potential health } \\
\text { effects }\end{array}$ & Ref. \\
\hline Mediterranean diet & $\begin{array}{l}\text { NFKB1, IKBKB, MMP9, IL1B, } \\
\text { MAPK8, XBP1 }\end{array}$ & - & $\begin{array}{l}\text { Anti-inflammatory, } \\
\text { antiatherogenic }\end{array}$ & {$[53]$} \\
\hline $\begin{array}{l}\text { Mediterranean diet plus olive } \\
\text { oil }\end{array}$ & NFKB1, MMP9, TNFA & - & $\begin{array}{l}\text { Anti-inflammatory, } \\
\text { antiatherogenic }\end{array}$ & {$[55]$} \\
\hline Mediterranean diet & NFE2L2, SOD1, SOD2, TXNRD1 & - & $\begin{array}{l}\text { Anti-inflammatory, } \\
\text { antioxidant }\end{array}$ & {$[54]$} \\
\hline High MUFA & $A P O B R$ & - & $\begin{array}{l}\text { Antilipidemic, } \\
\text { antiatherogenic }\end{array}$ & [56] \\
\hline Energy-restricted diet plus EPA & IL10 & + & Anti-inflammatory & {$[58]$} \\
\hline High PUFA & $P O M C, G A L P$ & + & Antiobesity & {$[57]$} \\
\hline High PUFA & HCRT, MCH & - & Antiobesity & [57] \\
\hline $\begin{array}{l}\text { Energy-restricted diet plus EPA } \\
\text { and } \alpha \text {-lipoic acid }\end{array}$ & Lipid catabolism genes & + & Antilipidemic & [59] \\
\hline $\begin{array}{l}\text { Energy-restricted diet plus EPA } \\
\text { and } \alpha \text {-lipoic acid }\end{array}$ & Lipid storage genes & - & Anti-lipidemic & [59] \\
\hline High protein & PPARGC1A, PCK1, GSTA, CPT1A & + & Antisteatotic & {$[60,61]$} \\
\hline High protein & $F G F 21, S C D 1$ & - & Antisteatotic & {$[60,61]$} \\
\hline Curcumin & MMP-9, MMP-13, EMMPRIN & - & $\begin{array}{l}\text { Antiatherogenic, } \\
\text { anticancer }\end{array}$ & {$[62,63]$} \\
\hline Resveratrol & EMMPRIN & - & Antiatherogenic & [64] \\
\hline Apple polyphenols & LEP, SREBF1, PLIN & - & Antiobesity & [65] \\
\hline Apple polyphenols & PPARGC1A, AQP7, AEBP1 & + & Antiobesity & [65] \\
\hline Flavonoid-fish oil supplement & $\begin{array}{l}\text { Phagocytosis-related } \\
\text { inflammatory genes }\end{array}$ & - & Anti-inflammatory & {$[145]$} \\
\hline High n-3/n-6 PUFA ratio & TLR4, TNFA, IL6, CRP & - & $\begin{array}{l}\text { Anti-inflammatory, } \\
\text { antidiabetic }\end{array}$ & [146] \\
\hline$\overline{\text { EGCG }}$ & $M M P 9, M M P 2$ & - & Antitumorigenic & {$[147,148]$} \\
\hline Theaflavin & MMP2 & - & Antitumorigenic & [149] \\
\hline Resveratrol & FASN & - & Antisteatotic & {$[150]$} \\
\hline Sulforaphane & EGR1 & + & Anticancer & {$[151]$} \\
\hline Genistein & $P 21, P 16$ & + & Anticancer & {$[152]$} \\
\hline Genistein & $B M I 1, c-M Y C$ & - & Anticancer & {$[152]$} \\
\hline
\end{tabular}

MUFA, monounsaturated fatty acids; PUFA, polyunsaturated fatty acids; NFKB1, nuclear factor kappa B subunit $1 ; I K B K B$, inhibitor of kappa light polypeptide gene enhancer in B-cells, kinase beta; $M M P 9$, matrix metallopeptidase 9; IL1B, interleukin 1 beta; MAPK8 (JNK1), mitogen-activated protein kinase 8; XBP1, X-box binding protein 1; TNFA, tumor necrosis factor alpha; $A P O B R$, apolipoprotein B receptor; NFE2L2, nuclear factor, erythroid 2 like 2; SOD1, superoxide dismutase 1; SOD2, superoxide dismutase 2; TXNRD1, thioredoxin reductase 1; IL10, interleukin 10; POMC, proopiomelanocortin; GALP, galanin like peptide; $H C R T$, hypocretin neuropeptide precursor; $M C H$, melaninconcentrating hormone; PPARGC1A, peroxisome proliferative activated receptor, gamma, coactivator 1 alpha; PCK1, phosphoenolpyruvatecarboxykinase 1;GSTA,glutathioneS-transferasecluster; CPT1A,carnitinepalmitoyltransferase 1A; FGF21, fibroblast growth factor 21; SCD1, stearoyl-coenzyme A desaturase 1; TLR4, toll-like receptor 4; IL6, interleukin 6; CRP, C-reactive protein; $M M P 2$, matrix metallopeptidase 2; MMP13, matrix metallopeptidase 13; EMMPRIN, extracellular matrix metalloproteinase inducer; FASN, fatty acid synthase; EGR1, early growth response 1; $L E P$, leptin; SREBF1, sterol regulatory element binding transcription factor 1; PLIN, perilipin; AQP7, aquaporin 7; $A E B P 1$, adipocyte enhancer binding protein 1.

\section{Diet and Epigenetic Signatures}

Epigenetics has been defined as "inheritable and reversible processes that regulate gene expression without concomitant changes in the DNA coding sequence" [70]. The epigenetic control of gene expression is involved in critical biological and physiological processes, such as imprinting, silencing of specific chromosomal domains, embryonic development, cellular differentiation, and organogenesis [71]. However, dysregulation of epigenetic phenomena 
Table 5. Nutriepigenetic examples of interactions between dietary intakes and epigenetic modifications involved in disease risk

\begin{tabular}{|c|c|c|c|c|}
\hline Dietary factors & Epigenetic signatures & $\begin{array}{l}\text { Modification } \\
\text { types }\end{array}$ & $\begin{array}{l}\text { Putative } \\
\text { disease risks }\end{array}$ & Ref. \\
\hline Low protein & NR1H3 acetylation & - & T2DM & {$[47]$} \\
\hline Chromium deficiency & Methylation of insulin signaling genes & + & T2DM & [49] \\
\hline Selenium deficiency & TLR2, ICAM1 methylation & - & CVD & {$[50]$} \\
\hline Vitamin $\mathrm{B}_{12}$ deficiency & SREBF1, LDLR methylation & - & Dyslipidemia & [51] \\
\hline Vitamin A deficiency & GATA4 methylation & + & CVD & [52] \\
\hline High fat and high sugar & LEP methylation & + & Obesity & [65] \\
\hline High fat & OPRM1, PENK, and DAT methylation & - & Obesity & [74] \\
\hline Low protein & CYP7A1 acetylation & - & Dyslipidemia & [75] \\
\hline $\begin{array}{l}\text { Choline and folate } \\
\text { deficiencies }\end{array}$ & $\begin{array}{l}\text { miR-134, miR-409-3p, miR-410 and } \\
\text { miR-495 expressions }\end{array}$ & + & NAFLD & [76] \\
\hline $\begin{array}{l}\text { Choline and folate } \\
\text { deficiencies }\end{array}$ & $\begin{array}{l}\text { miR-34a, miR-122, miR-181a, miR-192, } \\
\text { and miR-200b expressions }\end{array}$ & + & NAFLD & {$[77]$} \\
\hline $\begin{array}{l}\text { Low folate, vitamin } A \text {, } \\
\text { vitamin } B_{1} \text {, potassium, iron }\end{array}$ & $P 16, P 14$, and $h M L H 1$ methylation & + & Cancer & [78] \\
\hline Selenium deficiency & VHL methylation & + & Cancer & {$[79]$} \\
\hline Vitamin D deficiency & NFKBIA methylation & + & T2DM & [80] \\
\hline Calcium deficiency & HSD11B1 methylation & - & T2DM & [81] \\
\hline Magnesium deficiency & HSD11B2 methylation & + & T2DM & {$[82]$} \\
\hline High fat and high sugar & FASN methylation & - & Obesity, NAFLD & [88] \\
\hline $\begin{array}{l}\text { Choline and folate } \\
\text { deficiencies }\end{array}$ & APOE, FOXA1, and FOXA2 methylation & + & NAFLD & {$[144]$} \\
\hline High fat and high sugar & FASN methylation & - & Obesity, NAFLD & {$[153]$} \\
\hline $\begin{array}{l}\text { Low fruit consumption and } \\
\text { folate deficiency }\end{array}$ & LINE-1 methylation & - & Cancer & {$[154]$} \\
\hline
\end{tabular}

$L E P$, leptin; FASN, fatty acid synthase; OPRM1, opioid receptor, mu 1; PENK, preproenkephalin; DAT, dopamine transporter; CYP7A1, cytochrome P450 family 7 subfamily A member 1; NR1H3, nuclear receptor subfamily 1 group H member 3; LINE-1, long interspersed element-1; MLH1 (HMLH1), mutL homolog 1; APOE, apolipoprotein E; FOXA1, forkhead box A1; FOXA2, forkhead box A2; SREBF1, sterol regulatory element binding transcription factor 1; LDLR, low-density lipoprotein receptor; NFKBIA, NFKB inhibitor alpha; GATA4, GATA binding protein 4; TLR2, toll-like receptor 2; ICAM1, intercellular adhesion molecule 1; VHL, von Hippel-Lindau; HSD11B1, hydroxysteroid 11-beta dehydrogenase 1; HSD11B2, hydroxysteroid 11-beta dehydrogenase 2; CVD, cardiovascular disease; T2DM, type 2 diabetes mellitus; NAFLD, nonalcoholic fatty liver disease.

can alter phenotype and cell function, leading to the onset and progression of diverse chronic diseases $[72,73]$. In this sense, complex interactions among nutritional factors and DNA methylation, covalent histone modifications and noncoding RNAs, including microRNAs (miRNAs), have been implicated in obesity, dyslipidemia, T2DM, NAFLD, cancer, and CVD (Table 5). For example, high-fat and sugar diets have been related to abnormal methylation patterns of neuropeptide genes controlling food intake, which may contribute to the development of obesity [65, 74]. Low-protein diets induced glucose [47] and lipid alterations by disrupting histone modifications in key regulatory genes [75]. Also, choline and folate shortages enhanced miRNAs changes responsible for the progression of NAFLD [76, 77]. Different micronutrient deficiencies such as folate, vitamin A, vitamin B, potassium, iron, and selenium correlated with hypermethylation of tumor suppressor genes, demonstrating a role in cancer [78,79]. Deprivations of vitamin D [80], calcium [81], magnesium [82], and chromium [49] could increase the risk of developing T2DM through promoting aberrant methylation patterns in genes involved in glucose homeostasis, insulin signaling and inflammatory response. Additionally, deficits of selenium [50] and vitamin A were associated with the pathogenesis of CVD by affecting the DNA methylation status of critical genes [52]. 
Table 6. Certain nutriepigenetic studies evaluating epigenetic modifications related to diverse nutritional interventions

\begin{tabular}{|c|c|c|c|c|}
\hline Nutritional interventions & Epigenetic signatures & $\begin{array}{l}\text { Modification } \\
\text { types }\end{array}$ & $\begin{array}{l}\text { Potential health } \\
\text { effects }\end{array}$ & Ref. \\
\hline Apple polyphenols & SREBF1 methylation & - & Antiobesity & {$[65]$} \\
\hline Apple polyphenols & PPARGC1A methylation & + & Antiobesity & [65] \\
\hline Mediterranean diet & EEF2, IL4I1 methylation & - & Anti-inflammatory & [84] \\
\hline Mediterranean diet & MAPKAPK2 methylation & + & Anti-inflammatory & [84] \\
\hline Mediterranean diet & IL6 methylation & + & Anti-inflammatory & [85] \\
\hline Fish oil and pectin & $\begin{array}{l}\text { miR-19b, miR-26b, miR-203 } \\
\text { expressions }\end{array}$ & + & Anticancer & [86] \\
\hline$\overline{\mathrm{DHA}}$ & $\begin{array}{l}\text { miR-192, miR-30c } \\
\text { expressions }\end{array}$ & + & Antilipidemic & {$[87]$} \\
\hline Pterostilbene & FASN methylation & + & Antiobesity & {$[88]$} \\
\hline Curcumin & p300 HAT activity & - & CVD prevention & [89] \\
\hline Curcumin & $\begin{array}{l}\text { FGFR3, FZD10, GPX4, HOXD3 } \\
\text { methylation }\end{array}$ & - & Antifibrotic & [90] \\
\hline Resveratrol & $\begin{array}{l}\text { miR-129, miR-328-5p, } \\
\text { miR-539-5p }\end{array}$ & & Antilipidemic & {$[149]$} \\
\hline Genistein & $\begin{array}{l}\text { P21, P16 chromatin } \\
\text { activators }\end{array}$ & + & Anticancer & {$[151]$} \\
\hline Genistein & $\begin{array}{l}\text { P21, P16 chromatin } \\
\text { repressors }\end{array}$ & - & Anticancer & {$[151]$} \\
\hline $\begin{array}{l}\text { Methyl donor } \\
\text { supplementation }\end{array}$ & FASN methylation & + & Antisteatotic & [155] \\
\hline Extra-virgin olive oil & CNR1 (CB1) methylation & - & Anticancer & {$[156]$} \\
\hline PUFA & Global DNA methylation & + & Anticancer & [157] \\
\hline Resveratrol & BRCA-1 methylation & - & Anticancer & [158] \\
\hline Resveratrol & $\begin{array}{l}\text { miR-101b, miR- } 455 \\
\text { expressions }\end{array}$ & + & $\begin{array}{l}\text { Anti-inflammatory, } \\
\text { anticancer }\end{array}$ & [159] \\
\hline Resveratrol & Sirt1 activation & + & $\begin{array}{l}\text { Anti-inflammatory, } \\
\text { anticancer }\end{array}$ & {$[160,161]$} \\
\hline EGCG & $R X R A$ methylation & - & Anticancer & {$[162]$} \\
\hline EGCG & miR-16 expression & + & Anticancer & [163] \\
\hline $\begin{array}{l}\text { Green tea polyphenols } \\
\text { and EGCG }\end{array}$ & EZH2, class I HDAC activity & - & Anticancer & {$[164]$} \\
\hline $\begin{array}{l}\text { Green tea polyphenols } \\
\text { and EGCG }\end{array}$ & P53 acetylation & + & Anticancer & [165] \\
\hline Curcumin & miR-22 expression & + & Anticancer & {$[166]$} \\
\hline Sulforaphane & HDAC activity & - & Anticancer & {$[167,168]$} \\
\hline Sulforaphane & P21 acetylation & + & Anticancer & {$[168]$} \\
\hline Genistein & P21, P16 acetylation & + & Anticancer & [169] \\
\hline
\end{tabular}

DHA, docosahexaenoic acid; PUFA, polyunsaturated fatty acid; EGCG, epigallocatechin-3-gallate; EEF2, eukaryotic translation elongation factor 2; IL4I1, interleukin-4 induced 1; MAPKAPK2, mitogen-activated protein kinase-activated protein kinase 2; IL6, interleukin-6; CNR1 (CB1), cannabinoid receptor 1; BRCA1, DNA repair associated; sirt1, sirtuin 1; FASN, fatty acid synthase; RXRA, retinoid X receptor alpha; EZH2, enhancer of zeste homolog 2; FGFR3, fibroblast growth factor receptor 3; FZD10, frizzled class receptor 10; GPX4, glutathione peroxidase 4; HOXD3, homeobox D3; HATs, acetyltransferases; HDACs, histone deacetylases; H3, histone 3; ERS1, estrogen receptor 1 (alpha); SREBF1, sterol regulatory element binding transcription factor 1; PPARGC1A, peroxisome proliferative activated receptor, gamma, coactivator 1 alpha.

On the other hand, the reversible feature of epigenetic marks has given rise to the design of specific nutritional interventions aimed at reversing epigenetic alterations that might have a significant impact on preventing and treating human chronic diseases (nutriepigenetics) [83]. Thus, several experimental studies have investigated the epigenetic mechanisms underlying the health effects of certain nutrients and bioactive food components (Table 6). For instance, it was found that the anti-inflammatory effects of consuming a Mediterranean diet 
were related to hypermethylation of proinflammatory genes $[84,85]$. The administrations of polyunsaturated fatty acids positively modulated the expression of several miRNAs, which suppressed oncogenic and lipogenic genes [86, 87]. Also, the anticancer properties of resveratrol, epigallocatechin-3-gallate, curcumin, sulforaphane, and genistein have been associated with some epigenetic modifications including hypomethylation and acetylation of tumor suppressor genes, and an increase in miRNAs targeting oncogenes (Table 6). Likewise, apple polyphenols and pterostilbene (a derivate of resveratrol), prevented diet-induced obesity by regulating the methylation status of genes involved in lipid metabolism $[65,88]$. Furthermore, it was reported that curcumin exerted protective effects against liver injury and heart failure through modulating DNA methylation patterns and histone modifications of key genes [89, 90]. Based on this evidence, it has been proposed that the introduction of these dietary compounds into an "epigenetic diet" could serve as an effective strategy for reducing the incidence of obesity and associated comorbidities [91]. Additionally, studies have shown that some of the health benefits of energy restriction are mediated partially by epigenetic mechanisms including prevention of aberrant DNA methylation patterns and chromatin alterations [92]. Thus, it has been reported that moderate energy reductions might contribute to delay the onset of some aging-related diseases and extend lifespan through epigenetic mechanisms [93].

Of note, epigenetic marks have also been found to modulate the effect of nutritional treatments on weight loss and changes in metabolic profiles, which could be used as biomarkers to predict the responsiveness to dietary prescriptions [94]. For example, methylation levels of circadian genes correlated with the magnitude of weight loss and circulating blood lipids after a nutritional program based on a Mediterranean dietary pattern $[95,96]$. Similarly, methylation patterns of appetite-regulatory genes were associated with the success in weight loss or the risk of weight regain [97, 98]. Moreover, reductions of body fat and serum lipids were related to changes in the methylation status of genes involved in inflammatory response and fatty acid metabolism [99, 100]. Furthermore, differential baseline expression of several miRNAs was found between responders and nonresponders to a weight-loss trial that consisted of following an energy-restricted treatment [101].

As a final point, it is important to highlight that there may be interactions between the different genetic/epigenetic approaches, which may modulate the effectiveness of precision nutrition on the treatment of some chronic diseases. For example, in vitro studies demonstrated that the effects of omega-3 fatty acids supplementation on plasma triglyceride clearance through increasing transcription rates of lipoprotein lipase ( $L P L)$ gene, were dependent on the L162V polymorphism in the peroxisome proliferator-activated receptor alpha (PPARA) gene [102]. Another study reported that gene expression levels of PPARA and apolipoprotein A1 (APOA1) were influenced by the PPARA L162V polymorphism after the supplementation of omega-3 fatty acids [103]. Furthermore, it was found that changes in plasma triglycerides in response to omega-3 fatty acid supplementation could be modulated by the effect of polymorphisms and DNA methylation on expression levels of key genes identified by genome-wide association studies [104]. Additionally, genetic variants in genes encoding the selenoproteins glutathione peroxidase (GPX1) and selenoprotein P (SEPP) could influence their gene expressions in response to supplementation with a selenium-rich Brazil nut, suggesting a possible role in the nutritional treatment of chronic degenerative conditions [105].

\section{Concluding Remarks}

The adverse impacts of metabolic diseases including obesity and associated chronic comorbidities on public health remain a major concern due to the lack of effective interventions for their prevention and management. The absence of relevant progress despite 
persistent efforts may be partially explained by the fact that current strategies are based on nutritional recommendations for general populations, and do not consider the influence of genetic/epigenetic factors and their interaction with the environment (mainly diet and physical activity). Precision nutrition is an important part of personalized medicine and an emerging approach for disease prevention and treatment that takes into account genetic/ epigenetic information, as well as age, gender, physiopathological status and environmental issues, including personal lifestyle. In recent years, genomic sciences have been contributing to a better understanding of how genetic variants and epigenetic modifications are involved in the development of diverse pathological conditions and the way in which they may modify responses to therapy. This knowledge has led to the search for genetic and epigenetic biomarkers to predict the risk of developing chronic diseases. Another potential therapeutic target is the use of nutritional interventions based on certain nutrients and bioactive dietary compounds that can modify epigenetic marks and gene expression. Although caution must be exercised, these scientific insights are paving the way for the design of innovative strategies for the prevention, management, and treatment of obesity and other prevalent chronic diseases with a genetic background within the era of precision nutrition.

\section{References}

1 Ng M, Fleming T, Robinson M, Thomson B, Graetz N, Margono C, et al: Global, regional, and national prevalence of overweight and obesity in children and adults during 1980-2013: a systematic analysis for the Global Burden of Disease Study 2013. Lancet 2014;384:766-781.

2 Seidell JC, Halberstadt J: The global burden of obesity and the challenges of prevention. Ann Nutr Metab 2015; 66(suppl 2):7-12.

3 Lim SS, Vos T, Flaxman AD, Danaei G, Shibuya K, Adair-Rohani H, et al: A comparative risk assessment of burden of disease and injury attributable to 67 risk factors and risk factor clusters in 21 regions, 1990-2010: a systematic analysis for the Global Burden of Disease Study 2010. Lancet 2012;380:2224-2260.

4 Simopoulos AP: The impact of the Bellagio Report on healthy agriculture, healthy nutrition, healthy people: scientific and policy aspects and the International Network of Centers for Genetics, Nutrition and Fitness for Health. J Nutrigenet Nutrigenomics 2014;7:191-211.

5 Kang JX: Nutritional problems and solutions for the modern health epidemic. J Nutrigenet Nutrigenomics 2014; 7:188-190.

6 Steemburgo T, Azevedo MJ, Martínez JA: Gene-nutrient interaction and its association with obesity and diabetes mellitus. Arq Bras Endocrinol Metabol 2009;53:497-508.

7 Martínez JA, Milagro FI, Claycombe KJ, Schalinske KL: Epigenetics in adipose tissue, obesity, weight loss, and diabetes. Adv Nutr 2014;5:71-81.

8 Kohlmeier M, De Caterina R, Ferguson LR, Görman U, Allayee H, Prasad C, Kang JX, Nicoletti CF, Martinez JA: Guide and Position of the International Society of Nutrigenetics/Nutrigenomics on Personalized Nutrition. 2. Ethics, Challenges and Endeavors of Precision Nutrition. J Nutrigenet Nutrigenomics 2016;9:28-46.

9 Goni L, Cuervo M, Milagro FI, Martínez JA: Future perspectives of personalized weight loss interventions based on nutrigenetic, epigenetic, and metagenomic data. J Nutr DOI: 10.3945/jn.115.218354.

10 Aronson SJ, Rehm HL: Building the foundation for genomics in precision medicine. Nature 2015;526:336-342.

11 Ferguson LR, De Caterina R, Görman U, Allayee H, Kohlmeier M, Prasad C, Choi MS, Curi R, de Luis DA, Gil Á, Kang JX, Martin RL, Milagro FI, Nicoletti CF, Nonino CB, Ordovas JM, Parslow VR, Portillo MP, Santos JL, Serhan CN, Simopoulos AP, Velázquez-Arellano A, Zulet MA, Martinez JA: Guide and position of the International Society of Nutrigenetics/Nutrigenomics on Personalised Nutrition. 1. Fields of precision nutrition. J Nutrigenet Nutrigenomics 2016;9:12-27.

121000 Genomes Project Consortium, Auton A, Brooks LD, Durbin RM, Garrison EP, Kang HM, Korbel JO, Marchini JL, McCarthy S, McVean GA, Abecasis GR: A global reference for human genetic variation. Nature 2015;526: 68-74.

13 Simopoulos AP: Nutrigenetics/nutrigenomics. Annu Rev Public Health 2010;31:53-68.

14 Martínez JA: Perspectives on personalized nutrition for obesity. J Nutrigenet Nutrigenomics 2014; 7:I-III.

15 Meisel SF, Carere DA, Wardle J, Kalia SS, Moreno TA, Mountain JL, Roberts JS, Green RC; PGen Study Group: Explaining, not just predicting, drives interest in personal genomics. Genome Med 2015;7:74.

16 Ramos-Lopez O, Panduro A, Martinez-Lopez E, Roman S: Sweet taste receptor TAS1R2 polymorphism (Val191Val) is associated with a higher carbohydrate intake and hypertriglyceridemia among the population of West Mexico. Nutrients 2016;8:101. 
17 Ramos-Lopez O, Panduro A, Martinez-Lopez E, Fierro NA, Ojeda-Granados C, Sepulveda-Villegas M, Roman S: Genetic variant in the CD36 gene (rs1761667) is associated with higher fat intake and high serum cholesterol among the population of West Mexico. J Nutr Food Sci 2015;5:353.

18 Jiang-Hua Q, De-Chuang J, Zhen-Duo L, Shu-de C, Zhenzhen L: Association of methylenetetrahydrofolate reductase and methionine synthase polymorphisms with breast cancer risk and interaction with folate, vitamin B6, and vitamin B12 intakes. Tumour Biol 2014;35:11895-11901.

19 Ahn J, Yu K, Stolzenberg-Solomon R, Simon KC, McCullough ML, Gallicchio L, Jacobs EJ, Ascherio A, Helzlsouer K, Jacobs KB, Li Q, Weinstein SJ, Purdue M, Virtamo J, Horst R, Wheeler W, Chanock S, Hunter DJ, Hayes RB, Kraft P, Albanes D: Genome-wide association study of circulating vitamin D levels. Hum Mol Genet 2010;19: 2739-2745.

20 Barry EL, Rees JR, Peacock JL, Mott LA, Amos CI, Bostick RM, Figueiredo JC, Ahnen DJ, Bresalier RS, Burke CA, Baron JA: Genetic variants in CYP2R1, CYP24A1, and VDR modify the efficacy of vitamin D3 supplementation for increasing serum 25-hydroxyvitamin D levels in a randomized controlled trial. J Clin Endocrinol Metab 2014;99:E2133-E2137.

21 Desmarchelier C, Borel P, Goncalves A, Kopec R, Nowicki M, Morange S, Lesavre N, Portugal H, Reboul E: A combination of single-nucleotide polymorphisms is associated with interindividual variability in cholecalciferol bioavailability in healthy men. J Nutr 2016;146:2421-2428.

22 Stathopoulou MG, Dedoussis GV, Trovas G, Theodoraki EV, Katsalira A, Dontas IA, Hammond N, Deloukas P, Lyritis GP: The role of vitamin D receptor gene polymorphisms in the bone mineral density of Greek postmenopausal women with low calcium intake. J Nutr Biochem 2011;22:752-757.

23 Hosseini-Esfahani F, Mirmiran P, Daneshpour MS, Mehrabi Y, Hedayati M, Zarkesh M, Azizi F: Western dietary pattern interaction with APOC3 polymorphism in the risk of metabolic syndrome: Tehran Lipid and Glucose Study. J Nutrigenet Nutrigenomics 2014;7:105-117.

24 Hosseini-Esfahani F, Mirmiran P, Daneshpour MS, Mehrabi Y, Hedayati M, Soheilian-Khorzoghi M, Azizi F: Dietary patterns interact with APOA1/APOC3 polymorphisms to alter the risk of the metabolic syndrome: the Tehran Lipid and Glucose Study. Br J Nutr 2015;113:644-653.

25 Palatini P, Ceolotto G, Ragazzo F, Dorigatti F, Saladini F, Papparella I, Mos L, Zanata G, Santonastaso M: CYP1A2 genotype modifies the association between coffee intake and the risk of hypertension. J Hypertens 2009;27: 1594-1601.

26 Cornelis MC, El-Sohemy A, Kabagambe EK, Campos H: Coffee, CYP1A2 genotype, and risk of myocardial infarction. JAMA 2006;295:1135-1141.

27 Goni L, Cuervo M, Milagro FI, Martínez JA: A genetic risk tool for obesity predisposition assessment and personalized nutrition implementation based on macronutrient intake. Genes Nutr 2015;10:445.

28 Casas-Agustench P, Arnett DK, Smith CE, Lai CQ, Parnell LD, Borecki IB, Frazier-Wood AC, Allison M, Chen YD, Taylor KD, Rich SS, Rotter JI, Lee YC, Ordovás JM: Saturated fat intake modulates the association between an obesity genetic risk score and body mass index in two US populations. J Acad Nutr Diet 2014;114:1954-1966.

29 Qi Q, Chu AY, Kang JH, Jensen MK, Curhan GC, Pasquale LR, Ridker PM, Hunter DJ, Willett WC, Rimm EB, Chasman DI, Hu FB, Qi L: Sugar-sweetened beverages and genetic risk of obesity. N Engl J Med 2012;367: 1387-1396.

30 Qi Q, Chu AY, Kang JH, Huang J, Rose LM, Jensen MK, Liang L, Curhan GC, Pasquale LR, Wiggs JL, De Vivo I, Chan AT, Choi HK, Tamimi RM, Ridker PM, Hunter DJ, Willett WC, Rimm EB, Chasman DI, Hu FB, Qi L: Fried food consumption, genetic risk, and body mass index: gene-diet interaction analysis in three US cohort studies. BMJ 2014;348:g1610.

31 Huang T, Ley SH, Zheng Y, Wang T, Bray GA, Sacks FM, Qi L: Genetic susceptibility to diabetes and long-term improvement of insulin resistance and $\beta$ cell function during weight loss: the Preventing Overweight Using Novel Dietary Strategies (POUNDS LOST) trial. Am J Clin Nutr 2016;104:198-204.

32 Wang T, Huang T, Zheng Y, Rood J, Bray GA, Sacks FM, Qi L: Genetic variation of fasting glucose and changes in glycemia in response to 2-year weight-loss diet intervention: the POUNDS LOST trial. Int J Obes (Lond) 2016;40:1164-1169.

33 Rudkowska I, Guénard F, Julien P, Couture P, Lemieux S, Barbier O, Calder PC, Minihane AM, Vohl MC: Genomewide association study of the plasma triglyceride response to an $n-3$ polyunsaturated fatty acid supplementation. J Lipid Res 2014;55:1245-1253.

34 Fallaize R, Celis-Morales C, Macready AL, Marsaux CF, Forster H, O’Donovan C, Woolhead C, San-Cristobal R, Kolossa S, Hallmann J, Mavrogianni C, Surwillo A, Livingstone KM, Moschonis G, Navas-Carretero S, Walsh MC, Gibney ER, Brennan L, Bouwman J, Grimaldi K, Manios Y, Traczyk I, Drevon CA, Martinez JA, Daniel H, Saris WH, Gibney MJ, Mathers JC, Lovegrove JA; Food4Me Study: The effect of the apolipoprotein E genotype on response to personalized dietary advice intervention: findings from the Food4Me randomized controlled trial. Am J Clin Nutr 2016;104:827-836.

35 Livingstone KM, Celis-Morales C, Navas-Carretero S, San-Cristobal R, Macready AL, Fallaize R, Forster H, Woolhead C, O’Donovan CB, Marsaux CF, Kolossa S, Tsirigoti L, Lambrinou CP, Moschonis G, Godlewska M, Surwiłło A, Drevon CA, Manios Y, Traczyk I, Gibney ER, Brennan L, Walsh MC, Lovegrove JA, Saris WH, Daniel H, Gibney M, Martinez JA, Mathers JC; Food4Me Study: Effect of an Internet-based, personalized nutrition randomized trial on dietary changes associated with the Mediterranean diet: the Food4Me Study. Am J Clin Nutr 2016;104:288-297. 
36 Nielsen DE, El-Sohemy A: Disclosure of genetic information and change in dietary intake: a randomized controlled trial. PLoS One 2014;9:e112665.

37 Roke K: Exploration of the perceived and actual benefits of omega-3 fatty acids and the impact of FADS1 and FADS2 genetic information on dietary intake and blood levels of EPA and DHA. Appl Physiol Nutr Metab 2017; 42:333.

38 Nielsen DE, El-Sohemy A: A randomized trial of genetic information for personalized nutrition. Genes Nutr 2012; 7:559-566.

39 Jeon JP, Shim SM, Nam HY, Ryu GM, Hong EJ, Kim HL, Han BG: Copy number variation at leptin receptor gene locus associated with metabolic traits and the risk of type 2 diabetes mellitus. BMC Genomics 2010;11:426.

40 Falchi M, El-Sayed Moustafa JS, Takousis P, Pesce F, Bonnefond A, Andersson-Assarsson JC, et al: Low copy number of the salivary amylase gene predisposes to obesity. Nat Genet 2014;46:492-497.

41 Bonnefond A, Yengo L, Dechaume A, Canouil M, Castelain M, Roger E, Allegaert F, Caiazzo R, Raverdy V, Pigeyre M, Arredouani A, Borys JM, Lévy-Marchal C, Weill J, Roussel R, Balkau B, Marre M, Pattou F, Brousseau T, Froguel P: Relationship between salivary/pancreatic amylase and body mass index: a systems biology approach. BMC Med 2017;15:37.

42 Hameed I, Masoodi SR, Afroze D, Bhat RA, Naykoo NA, Mir SA, Mubarik I, Ganai BA: CTTTA deletion/insertion polymorphism in 3'-UTR of LEPR gene in type 2 diabetes subjects belonging to Kashmiri population. J Diabetes Metab Disord 2014;13:124.

43 Fenech M, El-Sohemy A, Cahill L, Ferguson LR, French TA, Tai ES, Milner J, Koh WP, Xie L, Zucker M, Buckley M, Cosgrove L, Lockett T, Fung KY, Head R: Nutrigenetics and nutrigenomics: viewpoints on the current status and applications in nutrition research and practice. J Nutrigenet Nutrigenomics 2011;4:69-89.

44 Ferguson LR: Nutrigenomics approaches to functional foods. J Am Diet Assoc 2009;109:452-458.

45 Bouchard-Mercier A, Paradis AM, Rudkowska I, Lemieux S, Couture P, Vohl MC: Associations between dietary patterns and gene expression profiles of healthy men and women: a cross-sectional study. Nutr J 2013;12:24.

46 Pellatt AJ, Slattery ML, Mullany LE, Wolff RK, Pellatt DF: Dietary intake alters gene expression in colon tissue: possible underlying mechanism for the influence of diet on disease. Pharmacogenet Genomics 2016;26:294306.

47 Vo TX, Revesz A, Sohi G, Ma N, Hardy DB: Maternal protein restriction leads to enhanced hepatic gluconeogenic gene expression in adult male rat offspring due to impaired expression of the liver $\mathrm{X}$ receptor. J Endocrinol 2013;218:85-97.

48 Tryndyak V, de Conti A, Kobets T, Kutanzi K, Koturbash I, Han T, Fuscoe JC, Latendresse JR, Melnyk S, Shymonyak S, Collins L, Ross SA, Rusyn I, Beland FA, Pogribny IP: Interstrain differences in the severity of liver injury induced by a choline- and folate-deficient diet in mice are associated with dysregulation of genes involved in lipid metabolism. FASEB J 2012;26:4592-4602.

49 Zhang Q, Sun X, Xiao X, Zheng J, Li M, Yu M, Ping F, Wang Z, Qi C, Wang T, Wang X: Dietary chromium restriction of pregnant mice changes the methylation status of hepatic genes involved with insulin signaling in adult male offspring. PLoS One 2017;12:e0169889.

50 Yang G, Zhu Y, Dong X, Duan Z, Niu X, Wei J: TLR2-ICAM1-Gadd45 $\alpha$ axis mediates the epigenetic effect of selenium on DNA methylation and gene expression in Keshan disease. Biol Trace Elem Res 2014;159:69-80.

51 Adaikalakoteswari A, Finer S, Voyias PD, McCarthy CM, Vatish M, Moore J, Smart-Halajko M, Bawazeer N, Al-Daghri NM, McTernan PG, Kumar S, Hitman GA, Saravanan P, Tripathi G: Vitamin B12 insufficiency induces cholesterol biosynthesis by limiting s-adenosylmethionine and modulating the methylation of SREBF1 and LDLR genes. Clin Epigenet 2015; 7:14.

52 Feng Y, Zhao LZ, Hong L, Shan C, Shi W, Cai W: Alteration in methylation pattern of GATA-4 promoter region in vitamin A-deficient offspring's heart. J Nutr Biochem 2013;24:1373-1380.

53 Yubero-Serrano EM, Gonzalez-Guardia L, Rangel-Zuñiga O, Delgado-Lista J, Gutierrez-Mariscal FM, PerezMartinez P, Delgado-Casado N, Cruz-Teno C, Tinahones FJ, Villalba JM, Perez-Jimenez F, Lopez-Miranda J: Mediterranean diet supplemented with coenzyme Q10 modifies the expression of proinflammatory and endoplasmic reticulum stress-related genes in elderly men and women. J Gerontol A Biol Sci Med Sci 2012;67:3-10.

54 Yubero-Serrano EM, Gonzalez-Guardia L, Rangel-Zuñiga O, Delgado-Casado N, Delgado-Lista J, Perez-Martinez P, Garcia-Rios A, Caballero J, Marin C, Gutierrez-Mariscal FM, Tinahones FJ, Villalba JM, Tunez I, Perez-Jimenez F, Lopez-Miranda J: Postprandial antioxidant gene expression is modified by Mediterranean diet supplemented with coenzyme Q(10) in elderly men and women. Age (Dordr) 2013;35:159-170.

55 Camargo A, Delgado-Lista J, Garcia-Rios A, Cruz-Teno C, Yubero-Serrano EM, Perez-Martinez P, GutierrezMariscal FM, Lora-Aguilar P, Rodriguez-Cantalejo F, Fuentes-Jimenez F, Tinahones FJ, Malagon MM, PerezJimenez F, Lopez-Miranda J: Expression of proinflammatory, proatherogenic genes is reduced by the Mediterranean diet in elderly people. Br J Nutr 2012;108:500-508.

56 Varela LM, Ortega-Gomez A, Lopez S, Abia R, Muriana FJ, Bermudez B: The effects of dietary fatty acids on the postprandial triglyceride-rich lipoprotein/apoB48 receptor axis in human monocyte/macrophage cells. J Nutr Biochem 2013;24:2031-2039.

57 Dziedzic B, Szemraj J, Bartkowiak J, Walczewska A: Various dietary fats differentially change the gene expression of neuropeptides involved in body weight regulation in rats. J Neuroendocrinol 2007;19:364-373.

58 Huerta AE, Prieto-Hontoria PL, Sáinz N, Martínez JA, Moreno-Aliaga MJ: Supplementation with $\alpha$-lipoic acid alone or in combination with eicosapentaenoic acid modulates the inflammatory status of healthy overweight or obese women consuming an energy-restricted diet. J Nutr 2016;pii:jn224105. 
59 Huerta AE, Prieto-Hontoria PL, Fernández-Galilea M, Escoté X, Martínez JA, Moreno-Aliaga MJ: Effects of dietary supplementation with EPA and/or $\alpha$-lipoic acid on adipose tissue transcriptomic profile of healthy overweight/obese women following a hypocaloric diet. Biofactors DOI: 10.1002/biof.1317.

60 Garcia-Caraballo SC, Comhair TM, Verheyen F, Gaemers I, Schaap FG, Houten SM, Hakvoort TB, Dejong CH, Lamers WH, Koehler SE: Prevention and reversal of hepatic steatosis with a high-protein diet in mice. Biochim Biophys Acta 2013;1832:685-695.

61 Garcia-Caraballo SC, Comhair TM, Houten SM, Dejong CH, Lamers WH, Koehler SE: High-protein diets prevent steatosis and induce hepatic accumulation of monomethyl branched-chain fatty acids. J Nutr Biochem 2014; 25:1263-1274.

62 Cao J, Han Z, Tian L, Chen K, Fan Y, Ye B, Huang W, Wang C, Huang Z: Curcumin inhibits EMMPRIN and MMP-9 expression through AMPK-MAPK and PKC signaling in PMA induced macrophages. J Transl Med 2014;12:266.

63 Cao F, Liu T, Xu Y, Xu D, Feng S: Curcumin inhibits cell proliferation and promotes apoptosis in human osteoclastoma cell through MMP-9, NF-кB and JNK signaling pathways. Int J Clin Exp Pathol 2015;8:6037-6045.

64 Huang Z, Wang C, Wei L, Wang J, Fan Y, Wang L, Wang Y, Chen T: Resveratrol inhibits EMMPRIN expression via P38 and ERK1/2 pathways in PMA-induced THP-1 cells. Biochem Biophys Res Commun 2008;374:517521.

65 Boqué N, de la Iglesia R, de la Garza AL, Milagro FI, Olivares M, Bañuelos O, Soria AC, Rodríguez-Sánchez S, Martínez JA, Campión J: Prevention of diet-induced obesity by apple polyphenols in Wistar rats through regulation of adipocyte gene expression and DNA methylation patterns. Mol Nutr Food Res 2013;57:1473-1478.

66 Mutch DM, Temanni MR, Henegar C, Combes F, Pelloux V, Holst C, Sørensen TI, Astrup A, Martinez JA, Saris WH, Viguerie N, Langin D, Zucker JD, Clément K: Adipose gene expression prior to weight loss can differentiate and weakly predict dietary responders. PLoS One 2007;2:e1344.

67 Mutch DM, Pers TH, Temanni MR, Pelloux V, Marquez-Quiñones A, Holst C, Martinez JA, Babalis D, van Baak MA, Handjieva-Darlenska T, Walker CG, Astrup A, Saris WH, Langin D, Viguerie N, Zucker JD, Clément K; DiOGenes Project: A distinct adipose tissue gene expression response to caloric restriction predicts 6-mo weight maintenance in obese subjects. Am J Clin Nutr 2011;94:1399-1409.

68 Goyenechea E, Parra D, Crujeiras AB, Abete I, Martínez JA: A nutrigenomic inflammation-related PBMC-based approach to predict the weight-loss regain in obese subjects. Ann Nutr Metab 2009;54:43-51.

69 Márquez-Quiñones A, Mutch DM, Debard C, Wang P, Combes M, Roussel B, Holst C, Martinez JA, HandjievaDarlenska T, Kalouskova P, Jebb S, Babalis D, Pfeiffer AF, Larsen TM, Astrup A, Saris WH, Mariman E, Clément K, Vidal H, Langin D, Viguerie N; DiOGenes Project: Adipose tissue transcriptome reflects variations between subjects with continued weight loss and subjects regaining weight 6 mo after caloric restriction independent of energy intake. Am J Clin Nutr 2010;92:975-984.

70 Choi SW, Claycombe KJ, Martinez JA, Friso S, Schalinske KL: Nutritional epigenomics: a portal to disease prevention. Adv Nutr 2013;4:530-532.

71 Jones PA, Baylin SB: The epigenomics of cancer. Cell 2007;128:683-692.

72 Campión J, Milagro F, Martínez JA: Epigenetics and obesity. Prog Mol Biol Transl Sci 2010;94:291-347.

73 Duthie SJ: Epigenetic modifications and human pathologies: cancer and CVD. Proc Nutr Soc 2011;70:47-56.

74 Vucetic Z, Kimmel J, Totoki K, Hollenbeck E, Reyes TM: Maternal high-fat diet alters methylation and gene expression of dopamine and opioid-related genes. Endocrinology 2010;151:4756-4764.

75 Sohi G, Marchand K, Revesz A, Arany E, Hardy DB: Maternal protein restriction elevates cholesterol in adult rat offspring due to repressive changes in histone modifications at the cholesterol 7alpha-hydroxylase promoter. Mol Endocrinol 2011;25:785-798.

76 Tryndyak VP, Marrone AK, Latendresse JR, Muskhelishvili L, Beland FA, Pogribny IP: MicroRNA changes, activation of progenitor cells and severity of liver injury in mice induced by choline and folate deficiency. J Nutr Biochem 2016;28:83-90.

77 Tryndyak VP, Latendresse JR, Montgomery B, Ross SA, Beland FA, Rusyn I, Pogribny IP: Plasma microRNAs are sensitive indicators of inter-strain differences in the severity of liver injury induced in mice by a cholineand folate-deficient diet. Toxicol Appl Pharmacol 2012;262:52-59.

78 Mas S, Lafuente MJ, Crescenti A, Trias M, Ballesta A, Molina R, Zheng S, Wiencke JK, Lafuente A: Lower specific micronutrient intake in colorectal cancer patients with tumors presenting promoter hypermethylation in p16(INK4a), p4(ARF) and hMLH1. Anticancer Res 2007;27:1151-1156.

79 Uthus E, Begaye A, Ross S, Zeng H: The von Hippel-Lindau (VHL) tumor-suppressor gene is down-regulated by selenium deficiency in Caco-2 cells and rat colon mucosa. Biol Trace Elem Res 2011;142:223-231.

80 Zhang H, Chu X, Huang Y, Li G, Wang Y, Li Y, Sun C: Maternal vitamin D deficiency during pregnancy results in insulin resistance in rat offspring, which is associated with inflammation and Ikb $\alpha$ methylation. Diabetologia 2014;57:2165-2172.

81 Takaya J, Iharada A, Okihana H, Kaneko K: A calcium-deficient diet in pregnant, nursing rats induces hypomethylation of specific cytosines in the $11 \beta$-hydroxysteroid dehydrogenase-1 promoter in pup liver. Nutr Res 2013;33:961-970.

82 Takaya J, Iharada A, Okihana H, Kaneko K: Magnesium deficiency in pregnant rats alters methylation of specific cytosines in the hepatic hydroxysteroid dehydrogenase-2 promoter of the offspring. Epigenetics 2011;6: 573-578.

83 Choi SW, Friso S: Epigenetics: a new bridge between nutrition and health. Adv Nutr 2010;1:8-16. 
84 Arpón A, Riezu-Boj JI, Milagro FI, Razquin C, Martínez-González MA, Corella D, Estruch R, Casas R, Fitó M, Ros E, Salas-Salvadó J, Martínez JA: Adherence to Mediterranean diet is associated with methylation changes in inflammation-related genes in peripheral blood cells. J Physiol Biochem DOI: 10.1007/s13105-017-0552-6.

85 Nicoletti CF, Nonino CB, de Oliveira BA, Pinhel MA, Mansego ML, Milagro FI, Zulet MA, Martinez JA: DNA methylation and hydroxymethylation levels in relation to two weight loss strategies: energy-restricted diet or bariatric surgery. Obes Surg 2016;26:603-611.

86 Shah MS, Schwartz SL, Zhao C, Davidson LA, Zhou B, Lupton JR, Ivanov I, Chapkin RS: Integrated microRNA and mRNA expression profiling in a rat colon carcinogenesis model: effect of a chemo-protective diet. Physiol Genomics 2011;43:640-654.

87 Gil-Zamorano J, Martin R, Daimiel L, Richardson K, Giordano E, Nicod N, García-Carrasco B, Soares SM, IglesiasGutiérrez E, Lasunción MA, Sala-Vila A, Ros E, Ordovás JM, Visioli F, Dávalos A: Docosahexaenoic acid modulates the enterocyte Caco-2 cell expression of microRNAs involved in lipid metabolism. J Nutr 2014;144:575585.

88 Gracia A, Elcoroaristizabal X, Fernández-Quintela A, Miranda J, Bediaga NG, M de Pancorbo M, Rimando AM, Portillo MP: Fatty acid synthase methylation levels in adipose tissue: effects of an obesogenic diet and phenol compounds. Genes Nutr 2014;9:411.

89 Morimoto T, Sunagawa Y, Kawamura T, Takaya T, Wada H, Nagasawa A, Komeda M, Fujita M, Shimatsu A, Kita T, Hasegawa K: The dietary compound curcumin inhibits p300 histone acetyltransferase activity and prevents heart failure in rats. J Clin Invest 2008;118:868-878.

90 Wu P, Huang R, Xiong YL, Wu C: Protective effects of curcumin against liver fibrosis through modulating DNA methylation. Chin J Nat Med 2016;14:255-264.

91 Hardy TM, Tollefsbol TO: Epigenetic diet: impact on the epigenome and cancer. Epigenomics 2011;3:503-518.

92 Li Y, Daniel M, Tollefsbol TO: Epigenetic regulation of caloric restriction in aging. BMC Med 2011;9:98.

93 Martin SL, Hardy TM, Tollefsbol TO: Medicinal chemistry of the epigenetic diet and caloric restriction. Curr Med Chem 2013;20:4050-4059.

94 Milagro FI, Mansego ML, De Miguel C, Martínez JA: Dietary factors, epigenetic modifications and obesity outcomes: progresses and perspectives. Mol Aspects Med 2013;34:782-812.

95 Milagro FI, Gómez-Abellán P, Campión J, Martínez JA, Ordovás JM, Garaulet M: CLOCK, PER2 and BMAL1 DNA methylation: association with obesity and metabolic syndrome characteristics and monounsaturated fat intake. Chronobiol Int 2012;29:1180-1194.

96 Samblas M, Milagro FI, Gómez-Abellán P, Martínez JA, Garaulet M: Methylation on the circadian gene BMAL1 is associated with the effects of a weight loss intervention on serum lipid levels. J Biol Rhythms 2016;31:308317.

97 Cordero P, Campion J, Milagro FI, Goyenechea E, Steemburgo T, Javierre BM, Martinez JA: Leptin and TNFalpha promoter methylation levels measured by MSP could predict the response to a low-calorie diet. J Physiol Biochem 2011;67:463-470.

98 Crujeiras AB, Campion J, Díaz-Lagares A, Milagro FI, Goyenechea E, Abete I, Casanueva FF, Martínez JA: Association of weight regain with specific methylation levels in the NPY and POMC promoters in leukocytes of obese men: a translational study. Regul Pept 2013;186:1-6.

99 Lopez-Legarrea P, Mansego ML, Zulet MA, Martinez JA: SERPINE1, PAI-1 protein coding gene, methylation levels and epigenetic relationships with adiposity changes in obese subjects with metabolic syndrome features under dietary restriction. J Clin Biochem Nutr 2013;53:139-144.

100 Martín-Núñez GM, Cabrera-Mulero R, Rubio-Martín E, Rojo-Martínez G, Olveira G, Valdés S, Soriguer F, Castaño L, Morcillo S: Methylation levels of the SCD1 gene promoter and LINE-1 repeat region are associated with weight change: an intervention study. Mol Nutr Food Res 2014;58:1528-1536.

101 Milagro FI, Miranda J, Portillo MP, Fernandez-Quintela A, Campión J, Martínez JA: High-throughput sequencing of microRNAs in peripheral blood mononuclear cells: identification of potential weight loss biomarkers. PLoS One 2013;8:e54319.

102 Rudkowska I, Caron-Dorval D, Verreault M, Couture P, Deshaies Y, Barbier O, Vohl MC: PPARalpha L162V polymorphism alters the potential of n-3 fatty acids to increase lipoprotein lipase activity. Mol Nutr Food Res 2010; 54:543-550.

103 Rudkowska I, Garenc C, Couture P, Vohl MC: Omega-3 fatty acids regulate gene expression levels differently in subjects carrying the PPARalpha L162V polymorphism. Genes Nutr 2009;4:199-205.

104 Vallée Marcotte B, Guénard F, Cormier H, Lemieux S, Couture P, Rudkowska I, Vohl MC: Plasma triglyceride levels may be modulated by gene expression of IQCJ, NXPH1, PHF17 and MYB in Humans. Int J Mol Sci 2017; 18:pii: E257.

105 Cardoso BR, Busse AL, Hare DJ, Cominetti C, Horst MA, McColl G, Magaldi RM, Jacob-Filho W, Cozzolino SM: Pro198Leu polymorphism affects the selenium status and GPx activity in response to Brazil nut intake. Food Funct 2016;7:825-833.

106 Ortega-Azorín C, Sorlí JV, Asensio EM, Coltell O, Martínez-González MÁ, Salas-Salvadó J, Covas MI, Arós F, Lapetra J, Serra-Majem L, Gómez-Gracia E, Fiol M, Sáez-Tormo G, Pintó X, Muñoz MA, Ros E, Ordovás JM, Estruch R, Corella D: Associations of the FTO rs 9939609 and the MC4R rs17782313 polymorphisms with type 2 diabetes are modulated by diet, being higher when adherence to the Mediterranean diet pattern is low. Cardiovasc Diabetol 2012;11:137. 
107 Sonestedt E, Roos C, Gullberg B, Ericson U, Wirfält E, Orho-Melander M: Fat and carbohydrate intake modify the association between genetic variation in the FTO genotype and obesity. Am J Clin Nutr 2009;90:14181425.

108 Lappalainen T, Lindström J, Paananen J, Eriksson JG, Karhunen L, Tuomilehto J, Uusitupa M: Association of the fat mass and obesity-associated (FTO) gene variant (rs9939609) with dietary intake in the Finnish Diabetes Prevention Study. Br J Nutr 2012;108:1859-1865.

109 Vimaleswaran KS, Bodhini D, Lakshmipriya N, Ramya K, Anjana RM, Sudha V, Lovegrove JA, Kinra S, Mohan V, Radha V: Interaction between FTO gene variants and lifestyle factors on metabolic traits in an Asian Indian population. Nutr Metab (Lond) 2016;13:39.

110 Koochakpoor G, Daneshpour MS, Mirmiran P, Hosseini SA, Hosseini-Esfahani F, Sedaghatikhayat B, Azizi F: The effect of interaction between melanocortin-4 receptor polymorphism and dietary factors on the risk of metabolic syndrome. Nutr Metab (Lond) 2016;13:35.

111 Phillips CM, Goumidi L, Bertrais S, Field MR, McManus R, Hercberg S, Lairon D, Planells R, Roche HM: Genenutrient interactions and gender may modulate the association between ApoA1 and ApoB gene polymorphisms and metabolic syndrome risk. Atherosclerosis 2011;214:408-414.

112 Ouhaibi-Djellouli H, Mediene-Benchekor S, Lardjam-Hetraf SA, Hamani-Medjaoui I, Meroufel DN, Boulenouar H, Hermant X, Saidi-Mehtar N, Amouyel P, Houti L, Goumidi L, Meirhaeghe A: The TCF7L2 rs7903146 polymorphism, dietary intakes and type 2 diabetes risk in an Algerian population. BMC Genet 2014;15:134.

113 Phillips CM, Goumidi L, Bertrais S, Field MR, McManus R, Hercberg S, Lairon D, Planells R, Roche HM: Dietary saturated fat, gender and genetic variation at the TCF7L2 locus predict the development of metabolic syndrome. J Nutr Biochem 2012;23:239-244.

114 Corella D, Arregui M, Coltell O, Portolés O, Guillem-Sáiz P, Carrasco P, Sorlí JV, Ortega-Azorín C, González JI, Ordovás JM: Association of the LCT-13910C >T polymorphism with obesity and its modulation by dairy products in a Mediterranean population. Obesity (Silver Spring) 2011;19:1707-1714.

115 Memisoglu A, Hu FB, Hankinson SE, Manson JE, De Vivo I, Willett WC, Hunter DJ: Interaction between a peroxisome proliferator-activated receptor gamma gene polymorphism and dietary fat intake in relation to body mass. Hum Mol Genet 2003;12:2923-2929.

116 Sevastianova K, Santos A, Kotronen A, Hakkarainen A, Makkonen J, Silander K, Peltonen M, Romeo S, Lundbom J, Lundbom N, Olkkonen VM, Gylling H, Fielding BA, Rissanen A, Yki-Järvinen H: Effect of short-term carbohydrate overfeeding and long-term weight loss on liver fat in overweight humans. Am J Clin Nutr 2012;96:727734.

117 Mansego ML, De Marco G, Ivorra C, Lopez-Izquierdo R, Morcillo S, Rojo-Martínez G, González-Albert V, Martinez F, Soriguer F, Martín-Escudero JC, Redon J, Chaves FJ: The nutrigenetic influence of the interaction between dietary vitamin E and TXN and COMT gene polymorphisms on waist circumference: a case control study. J Transl Med 2015;13:286.

118 Zhang X, Qi Q, Zhang C, Smith SR, Hu FB, Sacks FM, Bray GA, Qi L: FTO genotype and 2-year change in body composition and fat distribution in response to weight-loss diets: the POUNDS LOST Trial. Diabetes 2012;61: 3005-3011.

119 Zheng Y, Huang T, Zhang X, Rood J, Bray GA, Sacks FM, Qi L: Dietary fat modifies the effects of FTO genotype on changes in insulin sensitivity. J Nutr 2015;145:977-982.

120 Grau K, Cauchi S, Holst C, Astrup A, Martinez JA, Saris WH, Blaak EE, Oppert JM, Arner P, Rössner S, Macdonald IA, Klimcakova E, Langin D, Pedersen O, Froguel P, Sørensen TI: TCF7L2 rs7903146-macronutrient interaction in obese individuals' responses to a 10-wk randomized hypoenergetic diet. Am J Clin Nutr 2010;91:472-479.

121 Zhang X, Qi Q, Bray GA, Hu FB, Sacks FM, Qi L: APOA5 genotype modulates 2-y changes in lipid profile in response to weight-loss diet intervention: the Pounds Lost Trial. Am J Clin Nutr 2012;96:917-922.

122 Qi Q, Bray GA, Hu FB, Sacks FM, Qi L: Weight-loss diets modify glucose-dependent insulinotropic polypeptide receptor rs2287019 genotype effects on changes in body weight, fasting glucose, and insulin resistance: the Preventing Overweight Using Novel Dietary Strategies trial. Am J Clin Nutr 2012;95:506-513.

123 Qi Q, Durst R, Schwarzfuchs D, Leitersdorf E, Shpitzen S, Li Y, Wu H, Champagne CM, Hu FB, Stampfer MJ, Bray GA, Sacks FM, Shai I, Qi L: CETP genotype and changes in lipid levels in response to weight-loss diet intervention in the POUNDS LOST and DIRECT randomized trials. J Lipid Res 2015;56:713-721.

124 Qi Q, Zheng Y, Huang T, Rood J, Bray GA, Sacks FM, Qi L: Vitamin D metabolism-related genetic variants, dietary protein intake and improvement of insulin resistance in a 2 year weight-loss trial: POUNDS Lost. Diabetologia 2015;58:2791-2799.

125 Xu M, Ng SS, Bray GA, Ryan DH, Sacks FM, Ning G, Qi L: Dietary fat intake modifies the effect of a common variant in the LIPC gene on changes in serum lipid concentrations during a long-term weight-loss intervention trial. J Nutr 2015;145:1289-1294.

126 Xu M, Qi Q, Liang J, Bray GA, Hu FB, Sacks FM, Qi L: Genetic determinant for amino acid metabolites and changes in body weight and insulin resistance in response to weight-loss diets: the Preventing Overweight Using Novel Dietary Strategies (POUNDS LOST) trial. Circulation 2013;127:1283-1289.

127 Stocks T, Ängquist L, Hager J, Charon C, Holst C, Martinez JA, Saris WH, Astrup A, Sørensen TI, Larsen LH: TFAP2B -dietary protein and glycemic index interactions and weight maintenance after weight loss in the DiOGenes trial. Hum Hered 2013;75:213-219. 
128 Qi Q, Bray GA, Smith SR, Hu FB, Sacks FM, Qi L: Insulin receptor substrate 1 gene variation modifies insulin resistance response to weight-loss diets in a 2-year randomized trial: the Preventing Overweight Using Novel Dietary Strategies (POUNDS LOST) trial. Circulation 2011;124:563-571.

129 Huang T, Huang J, Qi Q, Li Y, Bray GA, Rood J, Sacks FM, Qi L: PCSK7 genotype modifies effect of a weight-loss diet on 2-year changes of insulin resistance: the POUNDS LOST trial. Diabetes Care 2015;38:439-444.

130 Goni L, Cuervo M, Milagro FI, Martínez JA: Gene-gene interplay and gene-diet interactions involving the MTNR1B rs10830963 variant with body weight loss. J Nutrigenet Nutrigenomics 2014;7:232-242.

131 Razquin C, Martinez JA, Martinez-Gonzalez MA, Fernández-Crehuet J, Santos JM, Marti A: A Mediterranean diet rich in virgin olive oil may reverse the effects of the -174G/C IL6 gene variant on 3-year body weight change. Mol Nutr Food Res 2010;54(suppl 1):S75-S82.

132 Jiménez-Gómez Y, López-Miranda J, Blanco-Colio LM, Marín C, Pérez-Martínez P, Ruano J, Paniagua JA, Rodríguez F, Egido J, Pérez-Jiménez F: Olive oil and walnut breakfasts reduce the postprandial inflammatory response in mononuclear cells compared with a butter breakfast in healthy men. Atherosclerosis 2009; 204:e70-e76.

133 van Dijk SJ, Feskens EJ, Bos MB, Hoelen DW, Heijligenberg R, Bromhaar MG, de Groot LC, de Vries JH, Müller M, Afman LA: A saturated fatty acid-rich diet induces an obesity-linked proinflammatory gene expression profile in adipose tissue of subjects at risk of metabolic syndrome. Am J Clin Nutr 2009;90:1656-1664.

134 Enos RT, Velázquez KT, Murphy EA: Insight into the impact of dietary saturated fat on tissue-specific cellular processes underlying obesity-related diseases. J Nutr Biochem 2014;25:600-612.

135 Huang XF, Han M, Storlien LH: The level of NPY receptor mRNA expression in diet-induced obese and resistant mice. Brain Res Mol Brain Res 2003;115:21-28.

136 Huang XF, Yu Y, Zavitsanou K, Han M, Storlien L: Differential expression of dopamine D2 and D4 receptor and tyrosine hydroxylase mRNA in mice prone, or resistant, to chronic high-fat diet-induced obesity. Brain Res Mol Brain Res 2005;135:150-161.

137 Wang X, Cheng M, Zhao M, Ge A, Guo F, Zhang M, Yang Y, Liu L, Yang N: Differential effects of high-fat-diet rich in lard oil or soybean oil on osteopontin expression and inflammation of adipose tissue in diet-induced obese rats. Eur J Nutr 2013;52:1181-1189.

138 Zhao M, Zang B, Cheng M, Ma Y, Yang Y, Yang N: Differential responses of hepatic endoplasmic reticulum stress and inflammation in diet-induced obese rats with high-fat diet rich in lard oil or soybean oil. PLoS One 2013; 8:e78620.

139 Alsiö J, Rask-Andersen M, Chavan RA, Olszewski PK, Levine AS, Fredriksson R, Schiöth HB: Exposure to a high-fat high-sugar diet causes strong up-regulation of proopiomelanocortin and differentially affects dopamine D1 and D2 receptor gene expression in the brainstem of rats. Neurosci Lett 2014;559:18-23.

140 la Fleur SE, van Rozen AJ, Luijendijk MC, Groeneweg F, Adan RA: A free-choice high-fat high-sugar diet induces changes in arcuate neuropeptide expression that support hyperphagia. Int J Obes (Lond) 2010;34:537-546.

141 Hao L, Huang KH, Ito K, Sae-Tan S, Lambert JD, Ross AC: Fibroblast growth factor 21 (Fgf21) gene expression is elevated in the liver of mice fed a high-carbohydrate liquid diet and attenuated by a lipid emulsion but is not upregulated in the liver of mice fed a high-fat obesogenic diet. J Nutr 2016;146:184-190.

142 Glen CD, McVeigh LE, Voutounou M, Dubrova YE: The effects of methyl-donor deficiency on the pattern of gene expression in mice. Mol Nutr Food Res 2015;59:501-506.

143 Roth CL, Elfers CT, Figlewicz DP, Melhorn SJ, Morton GJ, Hoofnagle A, Yeh MM, Nelson JE, Kowdley KV: Vitamin D deficiency in obese rats exacerbates nonalcoholic fatty liver disease and increases hepatic resistin and Tolllike receptor activation. Hepatology 2012;55:1103-1111.

144 Tryndyak VP, Han T, Fuscoe JC, Ross SA, Beland FA, Pogribny IP: Status of hepatic DNA methylome predetermines and modulates the severity of non-alcoholic fatty liver injury in mice. BMC Genomics 2016;17:298.

145 Cialdella-Kam L, Nieman DC, Knab AM, Shanely RA, Meaney MP, Jin F, Sha W, Ghosh S: A mixed flavonoid-fish oil supplement induces immune-enhancing and anti-inflammatory transcriptomic changes in adult obese and overweight women - a randomized controlled trial. Nutrients 2016;8:pii:E277.

146 Liu HQ, Qiu Y, Mu Y, Zhang XJ, Liu L, Hou XH, Zhang L, Xu XN, Ji AL, Cao R, Yang RH, Wang F: A high ratio of dietary n-3/n-6 polyunsaturated fatty acids improves obesity-linked inflammation and insulin resistance through suppressing activation of TLR4 in SD rats. Nutr Res 2013;33:849-858.

147 Sen T, Chatterjee A: Epigallocatechin-3-gallate (EGCG) downregulates EGF-induced MMP-9 in breast cancer cells: involvement of integrin receptor $\alpha 5 \beta 1$ in the process. Eur J Nutr 2011;50:465-478.

148 Sen T, Moulik S, Dutta A, Choudhury PR, Banerji A, Das S, Roy M, Chatterjee A: Multifunctional effect of epigallocatechin-3-gallate (EGCG) in downregulation of gelatinase-A (MMP-2) in human breast cancer cell line MCF-7. Life Sci 2009;84:194-204.

149 Sil H, Sen T, Moulik S, Chatterjee A: Black tea polyphenol (theaflavin) downregulates MMP-2 in human melanoma cell line A375 by involving multiple regulatory molecules. J Environ Pathol Toxicol Oncol 2010;29: 55-68.

150 Gracia A, Miranda J, Fernández-Quintela A, Eseberri I, Garcia-Lacarte M, Milagro FI, Martínez JA, Aguirre L, Portillo MP: Involvement of miR-539-5p in the inhibition of de novo lipogenesis induced by resveratrol in white adipose tissue. Food Funct 2016;7:1680-1688.

151 Yang M, Teng W, Qu Y, Wang H, Yuan Q: Sulforaphene inhibits triple negative breast cancer through activating tumor suppressor Egr1. Breast Cancer Res Treat 2016;158:277-286. 
152 Li Y, Chen H, Hardy TM, Tollefsbol TO: Epigenetic regulation of multiple tumor-related genes leads to suppression of breast tumorigenesis by dietary genistein. PLoS One 2013;8:e54369.

153 Uriarte G, Paternain L, Milagro FI, Martínez JA, Campion J: Shifting to a control diet after a high-fat, highsucrose diet intake induces epigenetic changes in retroperitoneal adipocytes of Wistar rats. J Physiol Biochem 2013;69:601-611.

154 Agodi A, Barchitta M, Quattrocchi A, Maugeri A, Canto C, Marchese AE, Vinciguerra M: Low fruit consumption and folate deficiency are associated with LINE-1 hypomethylation in women of a cancer-free population. Genes Nutr 2015;10:480.

155 Cordero P, Gomez-Uriz AM, Campion J, Milagro FI, Martinez JA: Dietary supplementation with methyl donors reduces fatty liver and modifies the fatty acid synthase DNA methylation profile in rats fed an obesogenic diet. Genes Nutr 2013;8:105-113.

156 Di Francesco A, Falconi A, Di Germanio C, Micioni Di Bonaventura MV, Costa A, Caramuta S, Del Carlo M, Compagnone D, Dainese E, Cifani C, Maccarrone M, D'Addario C: Extravirgin olive oil up-regulates $\mathrm{CB}_{1}$ tumor suppressor gene in human colon cancer cells and in rat colon via epigenetic mechanisms. J Nutr Biochem 2015; 26:250-258.

157 Huang Q, Wen J, Chen G, Ge M, Gao Y, Ye X, Liu C, Cai C: Omega-3 polyunsaturated fatty acids inhibited tumor growth via preventing the decrease of genomic DNA methylation in colorectal cancer rats. Nutr Cancer 2016; 68:113-119.

158 Papoutsis AJ, Borg JL, Selmin OI, Romagnolo DF: BRCA-1 promoter hypermethylation and silencing induced by the aromatic hydrocarbon receptor-ligand TCDD are prevented by resveratrol in MCF-7 cells. J Nutr Biochem 2012;23:1324-1332.

159 Altamemi I, Murphy EA, Catroppo JF, Zumbrun EE, Zhang J, McClellan JL, Singh UP, Nagarkatti PS, Nagarkatti M: Role of microRNAs in resveratrol-mediated mitigation of colitis-associated tumorigenesis in $\operatorname{Apc}(\mathrm{Min} /+)$ mice. J Pharmacol Exp Ther 2014;350:99-109.

160 Zhu X, Liu Q, Wang M, Liang M, Yang X, Xu X, Zou H, Qiu J: Activation of Sirt1 by resveratrol inhibits TNF- $\alpha$ induced inflammation in fibroblasts. PLoS One 2011;6:e27081.

161 Buhrmann C, Shayan P, Popper B, Goel A, Shakibaei M: Sirt1 is required for resveratrol-mediated chemopreventive effects in colorectal cancer cells. Nutrients 2016;8:145.

162 Morris J, Moseley VR, Cabang AB, Coleman K, Wei W, Garrett-Mayer E, Wargovich MJ: Reduction in promotor methylation utilizing EGCG (epigallocatechin-3-gallate) restores RXR $\alpha$ expression in human colon cancer cells. Oncotarget 2016; 7:35313-35326.

163 Tsang WP, Kwok TT: Epigallocatechin gallate up-regulation of miR-16 and induction of apoptosis in human cancer cells. J Nutr Biochem 2010;21:140-146.

164 Deb G, Thakur VS, Limaye AM, Gupta S: Epigenetic induction of tissue inhibitor of matrix metalloproteinase-3 by green tea polyphenols in breast cancer cells. Mol Carcinog 2015;54:485-499.

165 Thakur VS, Gupta K, Gupta S: Green tea polyphenols increase p53 transcriptional activity and acetylation by suppressing class I histone deacetylases. Int J Oncol 2012;41:353-361.

166 Sun M, Estrov Z, Ji Y, Coombes KR, Harris DH, Kurzrock R: Curcumin (diferuloylmethane) alters the expression profiles of microRNAs in human pancreatic cancer cells. Mol Cancer Ther 2008;7:464-473.

167 Myzak MC, Dashwood WM, Orner GA, Ho E, Dashwood RH: Sulforaphane inhibits histone deacetylase in vivo and suppresses tumorigenesis in Apc-minus mice. FASEB J 2006;20:506-508.

168 Clarke JD, Hsu A, Yu Z, Dashwood RH, Ho E: Differential effects of sulforaphane on histone deacetylases, cell cycle arrest and apoptosis in normal prostate cells versus hyperplastic and cancerous prostate cells. Mol Nutr Food Res 2011;55:999-1009.

169 Majid S, Kikuno N, Nelles J, Noonan E, Tanaka Y, Kawamoto K, Hirata H, Li LC, Zhao H, Okino ST, Place RF, Pookot D, Dahiya R: Genistein induces the p21WAF1/CIP1 and p16INK4a tumor suppressor genes in prostate cancer cells by epigenetic mechanisms involving active chromatin modification. Cancer Res 2008;68: 2736-2744. 